\title{
Operability assessment of high speed passenger ships based on human comfort criteria
}

\author{
Tahsin Tezdogan*, Atilla Incecik and Osman Turan \\ Department of Naval Architecture, Ocean and Marine Engineering, University of Strathclyde, 100 Montrose \\ Street, Glasgow, G4 0LZ, UK \\ *corresponding author; e-mail: tahsin.tezdogan@strath.ac.uk, phone: +44(0)1415484912
}

ABSTRACT

The growing popularity of passenger cruise lines means continual challenges are faced concerning both a vessel's design and its operational ability. Vessel dimensions, service speeds and performance rates are rapidly increasing to keep pace with this expanding interest. It is essential that vessels demonstrate high performances, even in adverse sea and weather conditions, and ensure the comfort of passengers and the safety of cargo.

A vessel's operability can be defined as the percentage of time in which the vessel is capable of performing her tasks securely. In order to calculate a vessel's operability index, many key parameters are required. These include the dynamic responses of the ship to regular waves, the wave climate of the sea around the ship's route, and the assigned missions of the vessel.

This paper presents a procedure to calculate the operability index of a ship using seakeeping analyses. A discussion of the sensitivity of the results relative to three different employed seakeeping methods is then given. The effect of seasonality on a ship's estimated operability is also investigated using wave scatter diagrams. Finally, a high speed catamaran ferry is explored as a case study and its operability is assessed with regards to human comfort criteria.

\section{Keywords: Operability, Seakeeping, Passenger Vessels, Human Comfort, Strip Theory, Potential Theory}

\section{INTRODUCTION}

Recently, a rapid increase has been seen in the number of passengers travelling worldwide by passenger vessels. Annually, throughout the world, it is estimated that roughly 10 million people travel on over 230 cruise vessels (Riola and Arboleya, 2006). A key responsibility of naval architects is to ensure the comfort and well-being of such passengers.

Due to the dynamic nature of a seaway, a vessel's performance and safety are often disrupted by enormous dynamic loads, motions and accelerations. Such factors may seriously affect both the well-being and safety of the passengers and crew, leading to motion sickness and similar motion-induced forms of discomfort.

For this reason, an operability analysis, considering human comfort criteria, plays a vital role in ship design, especially for the design of passenger ships -from leisure crafts, to extremely large cruisers. Considerable investment is made when building a passenger vessel. The comfort level of the passengers is of paramount importance, and must be maintained above a specific threshold. This threshold must therefore be continually considered during the design of a passenger vessel. This should be quantified by applying an operability assessment procedure invoking seakeeping analyses in accordance with reliable seakeeping criteria.

The major parameters which are required to perform such an operability analysis can be divided into the following three main categories:

i) vessel geometry and loading condition

ii) definition of the seaway and wave data 
iii) limiting criteria

An overview of the operability assessment procedure is illustrated in Figure 1.

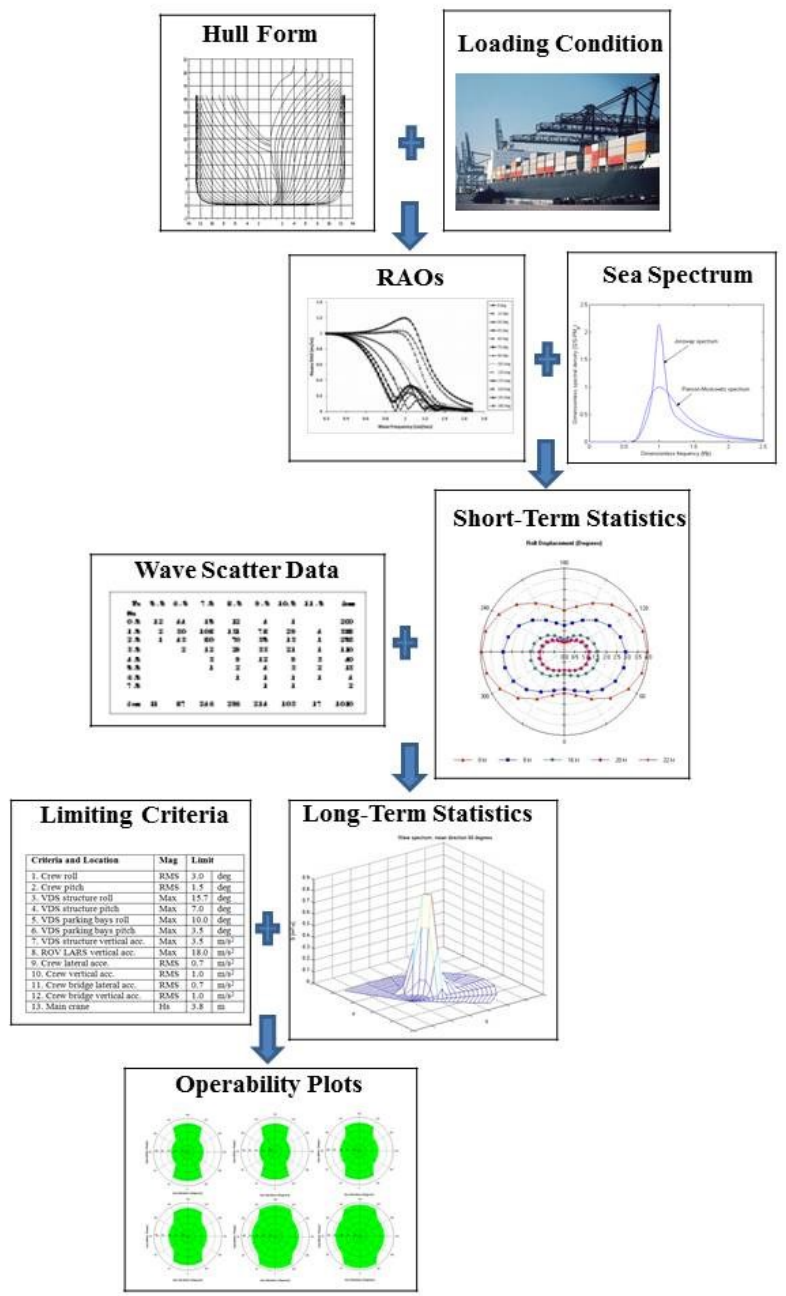

Figure 1. Overview of the operability analysis procedure (RAO: Response Amplitude Operator).

Figure 1 demonstrates that knowledge of both a vessel's hull form, and its loading conditions (such as draft, trim, centre of gravity and radii of gyration), are necessary to predict a ship's responses to regular waves (such as RAOs). The literature offers a wealth of seakeeping techniques which can be employed at this stage, ranging from simple strip theory to complex, fully non-linear Reynolds-Average Navier-Stokes (RANS) computations. Since each method has a different theoretical background, with associated limitations, the selection and use of a particular method will greatly affect the prediction of RAOs. The results of an operability analysis will therefore be dependent on the seakeeping technique employed. This paper will demonstrate this effect.

The seaway where the ship operates may be represented by sea spectrums dedicated to different specific sea areas. Short-term responses of the vessel are easily derived by combining the RAOs with the incident wave spectrum. However, it is of note that a ship encounters many different sea states on her voyage. It is therefore desirable to know the frequency of occurrence of wave height and wave period combinations in a specific geographic site. This data is generally found in wave scatter diagrams (WSD), which can be given yearly, monthly, or seasonally. Once wave scatter data is obtained, long term responses can be computed by means of statistical techniques. As seasons change, wave scatter data in a geographic area varies accordingly. As expected, this change can remarkably affect a vessel's 
operability. The paper also argues the effect of seasonality on the expected ship operability in a comparative manner.

The paper begins with a brief review of the literature on a ship's operability and seakeeping methods. Afterwards, an overview of the procedure for operability assessment is presented. Each stage of the methodology is introduced in detail in the subsequent sub-sections. A high speed car/passenger ferry operating in the west coast of Scotland is then explored as a case study, and the operability indices of the vessel are calculated. The results explicitly reveal the influence of seasonality on the predicted ship operability. The paper also investigates the sensitivity of the operability index to the adopted seakeeping technique to generate an RAO database. Finally, all of the results drawn from this work are briefly assessed in the last section.

\section{BACKGROUND}

The history of prediction of ship motions starts with Froude's novel study on rolling (Froude, 1861). Sources such as Newman (1978) and Beck and Reed (2001) can be referred to for a detailed historical approach to seakeeping.

Two developments in the 1950's pioneered modern seakeeping computations. The first development was the proposal of the random process theory to obtain short term responses to an irregular sea, and the second one was associated with the development of linear ship motion theories to obtain ship responses to regular waves (Beck and Reed, 2001).

St. Denis and Pierson (1953) pioneered a new method to estimate the statistics of ship motions in a seaway, which involved the application of spectral methods. This original theory was based on two fundamental assumptions:

- The sea surface has an ergodic Gaussian distribution,

- There is a linear relationship between wave elevation, wave loads and ship motions.

The transfer functions can be computed either experimentally or numerically. Experimental methods are generally used for the validation of numerical results since conducting experiments for each ship speed and heading would be very expensive and time consuming. There is therefore a wide range of commercial software available, which can calculate the RAOs of a desired vessel within a few minutes.

Viscosity is neglected in most seakeeping analyses, meaning that potential theory is still a very popular technique. However, some empirical viscous corrections are employed in the potential theory-based methods in an attempt to incorporate viscous effects into the formulation.

Beck and Reed (2001) estimate that $80 \%$ of all seakeeping computations at forward speeds are still performed using strip theory, because its fast, reliable solutions have sufficient accuracy for engineering purposes. Another advantage of strip theory is that it is also applicable to most conventional hull forms. However, discrepancies between strip theory and experiments for higher speed vessels, or highly non-wall sided hull forms, have motivated research to develop more advanced theories, such as the 3-D Rankine panel method, unsteady RANS methods and Large Eddy Simulation (LES) methods (Beck and Reed, 2001).

As discussed by Newman (1978), the conventional strip theory shows deficiencies both for low encounter frequencies and high speeds, due to assumptions used in the theory. When the theory is applied to low encounter frequencies, some fundamental problems occur, stemming from the evolution of forward speed effects and the complex nature of the diffraction problem in short incoming waves. The conventional strip theory is therefore questionable at low encounter frequencies and this is visible in the trend of a two-dimensional heave added mass 
curve plotted against the frequency of oscillation, as shown in Figure 2. As the frequency of encounter goes to zero $\left(\omega_{\mathrm{e}} \rightarrow 0\right)$, the added mass coefficients for vertical motions exponentially become infinite $(\mathrm{a} \rightarrow \infty)$. For this reason, strip theory is named a shortwavelength (high frequency) theory (Beck and Reed, 2001). The other problem strip theory undergoes is related to forward speed effects. In strip theory, the forward speed has a direct bearing on the hydrodynamic force due to the simple introduction of terms which are proportional to $\left(\mathrm{U} / \omega_{\mathrm{e}}\right)$ and $\left(\mathrm{U} / \omega_{\mathrm{e}}\right)^{2}$ (where $\mathrm{U}$ denotes forward speed). Faltinsen and Zhao (1991b) also point out that strip theory is the most robust theory when applied at a moderate forward speed of a vessel, though it is dubious for high speed applications because it models the interaction with the forward speed in a simplistic way. Furthermore, the effect of the local steady flow around the vessel is omitted.

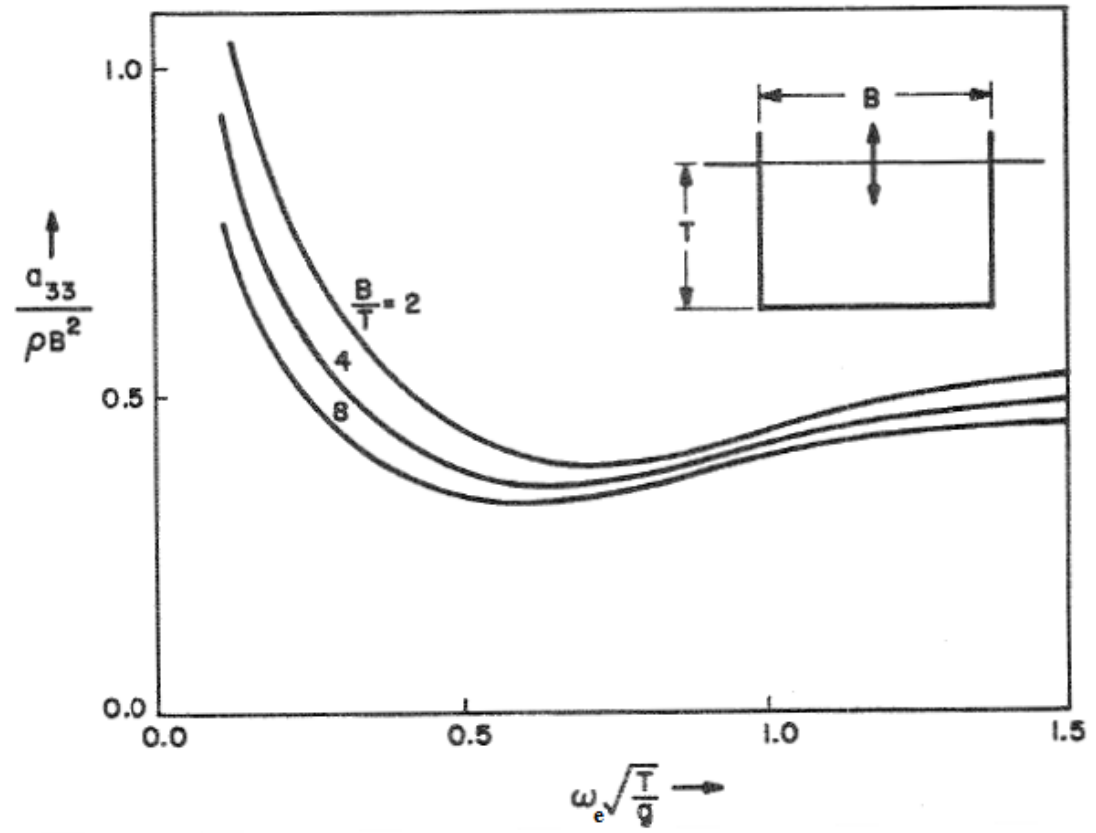

Figure 2. Added mass coefficients for a family of 2-D rectangular cylinders, based on the computations of Vugts (1968), taken from Newman (1978)

(a33: heave added mass, $\rho$ : fluid density, $\omega_{\mathrm{e}}$ : frequency of encounter, $\mathrm{T}$ : draft of the cylinder and B: beam of the cylinder).

As computers become more powerful, the use of 3-D techniques to investigate seakeeping problems is more common. Principally, there are two methods to solve three-dimensional features of seakeeping problems at a forward speed, namely, the Neumann-Kelvin theory (Brard, 1972 and Guevel et al., 1974) and the Dawson (double-body) method (Dawson, 1977). In the Neumann-Kelvin theory, the body boundary condition is satisfied about the mean position of the body, and the problem is solved using the free surface Green function with panels distributed over the mean hull surface. In the Dawson approach, the free surface linearisation is about the double-body flow, and Rankine source methods are treated with source distribution over the free surface and the body surface (Wang, 2000, Beck and Reed, 2001).

Yasukawa (2003) claims that 3-D Rankine panel methods have been developed to overcome the deficiencies in the strip theory methods. He suggests that for a detailed review of Rankine singularity methods, Bertram and Yasukawa (1996) and Bertram (1998) may be consulted. In the theory developed by Bertram and Yasukawa (1996), fully 3-D effects of the flow and forward speed are taken into account, in contrast to strip theory where these effects are not properly accounted for. Yasukawa (2003) applied the theory of Bertram and Yasukawa (1996) in the time domain to several container ships with strong flare. As a result of his 
validation study, it was found that hydrodynamic forces, ship motions and local pressures are much better predicted than those obtained by strip theory when compared with experiments. However, the calculated lateral hydrodynamic forces are not satisfactory, owing to the viscous flow effect. The author suggests that this problem can be reduced by applying empirical corrections, similar to those employed in strip theory.

Unfortunately, due to the fact that running a three-dimensional code is a demanding process, 3-D techniques require large amounts of computational power (Hermundstad et al., 1999). Therefore, a compromise between 2-D and 3-D methods has been made and a new approach to treat the nonlinear problem in the down-stream direction has been developed. This theory is the so-called high-speed slender body theory, or 2.5-D theory.

The majority of ship geometries are elongated, with their breadth and draft of the same order of magnitude relative to the length. This geometric feature is the basis of the slender-body assumptions, first used in the steady-state wave resistance problem by Cummins (1956). Another noteworthy restriction from the theory is that the ship is slender compared to the characteristic incident wavelength. As a consequence of this, the beam and draft are thought small relative to both the wavelength scale $\mathrm{U}^{2} / \mathrm{g}$ and the ship length L. Similarly, the Froude number $\left(\mathrm{Fn}=\mathrm{U} /(\mathrm{gL})^{0.5}\right)$ is assumed to be of order one (g denotes gravitational acceleration). The slender body theories are therefore termed long-wavelength theories (Newman, 1978).

As explained by Wang (2000), in the slender-body theories, the inner fluid is treated as twodimensional, whereas the outer solution for the far-field is treated as three-dimensional. Many different slender body theories have been developed regarding the different treatments of the inner two-dimensional problem, such as the original slender body theory (Newman, 1964), the unified slender body theory (Newman, 1978), the high speed slender body theory (Chapman, 1975), and the new slender body theory (Yueng and Kim, 1985).

Faltinsen and Zhao (1991a, b), on the other hand, treated the two-dimensional problem by using a hybrid boundary element method in their high-speed slender body theory. The simple source-dipole distribution is applied in the inner region, whereas the outer region benefits from analytical wave-free expressions. By using this method, the important diverging wave system around a high speed hull is accurately incorporated, whereas the transverse waves, which are very significant at lower speeds, cannot be included in the theory. Consequently, this method is only convenient to high speed ships. Numerically, only a side of the vessel is discretised to decrease computational effort. However, it is still possible to incorporate hydrodynamic interactions between demi-hulls within the theory. If the hull interaction is not accounted for, this means the effect of the other demi hull is neglected while calculating the velocity potential of one hull (Hermundstad et al., 1999).

As discussed by Wang (2000), despite the slender body theory being more rational than the conventional strip theory from a physical point of view, it is not extensively used due to its arduous and difficult numerical evaluation of the coefficients. According to real case studies performed by Sclavounos $(1984,1985)$ at $\mathrm{Fn}=0.2$ and 0.35 , as the exciting force is calculated more accurately in the slender-body theories, the ship motion predictions are not significantly better than those from the linear strip theory. Also, it is revealed by ITTC (1987) that the slender body theory gives no advantage over the strip theory for predicting a ship's vertical motions at forward speed, though it does demonstrate advantages for the prediction of sway and yaw motions.

As mentioned above, there are several methods to determine the response operators. Each technique features different assumptions and limitations, and therefore the output from a given technique will have a significant impact on the operability calculations. In order to 
highlight this problem, three particular methods will be employed to estimate the RAOs of the ferry. These are:

- Theory 1: Conventional strip theory formulation (2-D)

- Theory 2: High-speed formulation in which hull interaction is not included (21/2-D)

- Theory 3: High-speed formulation in which hull interaction is included (21/2-D)

In order to apply these theories in the operability calculations, VERES, which is based on a linear, potential, strip theory software package, is used in this study (Fathi, 2004). The fluid is assumed to be homogeneous, non-viscous, irrotational and incompressible. However, viscous roll damping is taken into account in this seakeeping package, employing some empirical formulae. For more information, the theory manual of the software can be consulted (Fathi and Hoff, 2013).

Theory 1 is based on the strip theory formulation by Salvesen, Tuck and Faltinsen (1970), which is particular to low ship speeds. The restrictions of this theory were explained above.

Theory 2 is based on a strip theory approach of Faltinsen and Zhao (1991a) and Faltinsen et al. (1991, 1992), and is briefly explained by Fathi and Hoff (2013): "The high-speed formulation is based on a strip theory approach, where the free-surface condition is used to step the solution in the downstream direction. The solution is started assuming that both the velocity potential and its x-derivative are zero at the first strip, counted from the bow". Hoff (2014) describes the principal difference between the traditional strip theory and the high speed formulation as that both formulations solve a two dimensional problem for each strip, but only the high speed formulation accounts for the interaction between the solutions of each strip by stepping the solution in the downstream direction.

In Theory 3, the forces exerted on the ship are directly calculated from the velocity potentials, employing integral theorems, similar to Theory 1. In the high speed formulation without hull interaction (Theory 2), the forces are calculated by integration of the pressure over the hull surface. Hermundstad et al. (1999) has found that these two methods (Theory 2 and 3) result in differences in the calculated heave and pitch motions; particularly around resonance.

There is wave interference between the waves generated by each single hull of a catamaran. Faltinsen (2005) defines this wave interference as follows "the waves generated from each hull are superimposed without accounting for the fact that the waves generated by one hull will be modified because of the presence of another hull'. The waves generated by one hull may become incident to another demihull, causing wave diffraction to occur. In the theory, a first assessment to determine whether any wave interaction is expected between the two side hulls of a catamaran can be performed by assuming there is no hydrodynamic hull interaction. The wave angle $\left(\alpha_{c}\right)$, given by Eq. 1, can then be calculated, to determine whether the waves inside the wave angle become incident to the other hull. It should also be highlighted that Theory 3 is capable to account for this diffraction effect occurring between the demihulls of a catamaran (Faltinsen, 2005).

$$
\begin{aligned}
& \tan \alpha_{c}=\frac{g}{2 U \omega_{e}} \\
& \frac{L_{1}}{L}=1-\left(\frac{b_{1}+0.5 b_{2}}{L}\right) 2 \frac{\omega_{e} U}{g}
\end{aligned}
$$

where $b_{2}$ is the beam of a single hull and $b_{1}$ is the distance between hull sides, as shown in Figure 3. $\mathrm{L}$ is the ship length and $\mathrm{L}_{1}$ is the length of the aft part of the side which is affected by the other hull. Throughout this paper, $\omega_{\mathrm{e}}$ denotes the frequency of encounter and gravitational acceleration $g$ is taken as $9.81 \mathrm{~m} / \mathrm{sec}^{2}$. 


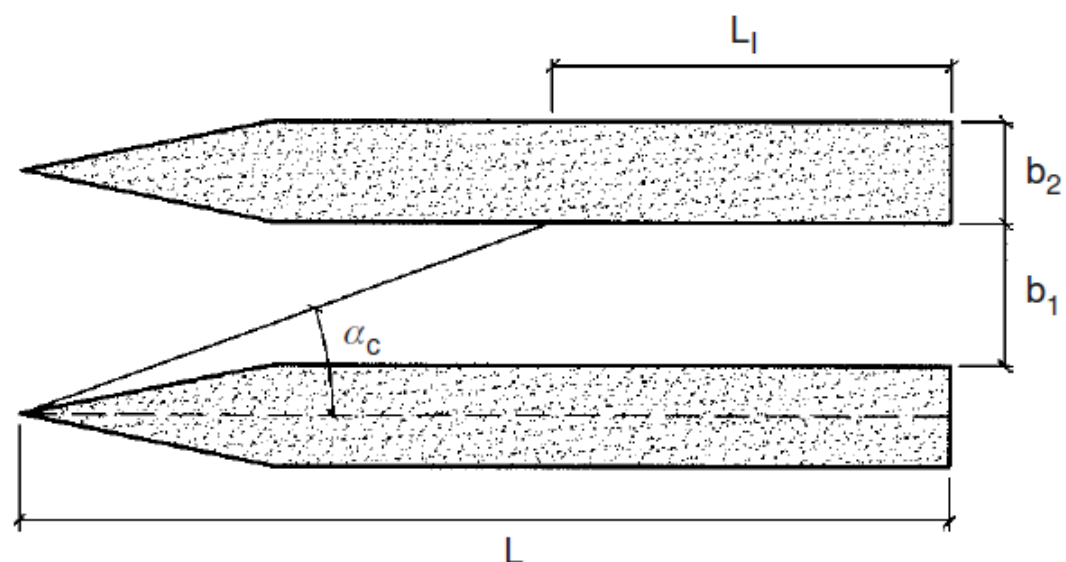

Figure 3. Hull interaction in a catamaran due to the wave effect, taken from Faltinsen (2005).

Each of the methods explained above will be used to independently calculate the motion responses of the ferry to regular waves, for a range of wave headings, to predict its operability. It should be stated that a $0^{\circ}$ wave headings $\left(\beta=0^{\circ}\right)$ corresponds to a head sea condition in this paper.

Operability and habitability assessments have been conducted for a variety of ship types by many researchers. Some of their conclusions have had an impact on operability analyses of passenger ships, specifically with regards to human comfort. O'Hanlon and McCauley (1974) and McCauley et al. (1976) conducted simulation trials to investigate motion sickness caused by a ship's vertical sinusoidal motions. Their work was then combined with seakeeping analysis techniques (Salvesen et al. 1970, McTaggart 1997), leading to the development of several suitable methods for the operability analysis of passenger ferries.

Ikeda et al. (1991) proposed a method to estimate the ratio of motion sick people on-board a ferry, by combining strip theory with O'Hanlon and McCauley's (1974) research. The operational performance of passenger ferries was evaluated by Dallinga et al. (2002) considering the influence of the motion sickness on passengers and crew. In addition, Sarioz, K. and Sarioz, E. (2005) investigated the effect of limiting criteria on the seakeeping performance assessment for passenger vessels and concluded that the expected seakeeping performance of a passenger vessel is entirely related to the magnitude of the defined limiting criteria. They evaluated habitability of the passenger vessel based solely on vertical accelerations defined by the ISO 2631/3 standard (ISO, 1985). Tezdogan et al. (2013) also presented operability analyses of two high speed car/passenger ferries. RAO databases of the crafts were generated using 2.5-D high speed theory. Their study explored the optimal vessel configuration and loading condition, with regards to operability.

Several researchers have carried out operability analyses on other ship types. Soares et al. (1995) offered a simple procedure for the seakeeping performance assessment of a fishing vessel. Then, Fonseca and Soares (2002) proposed a methodology to assess the seakeeping performance of vessels and argued the sensitivity of the results in relation to the use of various limiting criteria. They also revealed the influence of seasonality on the ship operability by comparing winter statistics to the annual statistics. The calculation of operability indices and the sensitivity analyses were performed for both a container ship and a fishing vessel in their study. Mortola et. al (2012) proposed an operability evaluation methodology and developed a decision-making support tool to rapidly assess and compare the operability of the two candidate vessels, to provide an operational and maintenance support service to offshore wind farms. 


\section{METHODOLOGY}

The methodology towards the prediction of the operability of ships is briefly presented in this section.

The operability assessment technique typically begins with the calculation of motion characteristics of the given ship for all headings at the sea area which is particular to the vessel's course. Then, these responses (RAOs) are combined with the wave spectrum to predict the short-term responses to irregular seas. Next, limiting significant wave heights are calculated for each seakeeping criterion by utilising the short term responses. Finally, the calculation of the operability index, which is the percentage of the number of wave height and wave period combinations not violating the predetermined criteria, can be computed taking into account long term statistics of the wave data.

A high speed catamaran car/passenger ferry is used in this paper as a case study to argue the effect of the various methods to predict RAOs. The main characteristics and geometry of the ferry are given in Table 1 and Figure 4, respectively.

Table 1. Main characteristics of the catamaran ferry (Tezdogan et al., 2013)

\begin{tabular}{ll}
\hline Length between perpendiculars $\left(\mathrm{L}_{\mathrm{BP}}\right)$ & $151.12 \mathrm{~m}$ \\
Overall beam of twin-hull $\left(\mathrm{B}_{\mathrm{OA}}\right)$ & $36.72 \mathrm{~m}$ \\
Beam of demi-hull $\left(\mathrm{B}_{\mathrm{DH}}\right)$ & $10.68 \mathrm{~m}$ \\
Design draught $(\mathrm{T})$ & $9.4 \mathrm{~m}$ \\
Displacement $(\Delta)$ & $16,448 \mathrm{~m}^{3}$ \\
Hull centre line spacing & $26.04 \mathrm{~m}$ \\
Longitudinal centre of gravity (LCG) aft of amidships & $11.84 \mathrm{~m}$ \\
Vertical centre of gravity $(\mathrm{VCG})$ from the base line & $13.28 \mathrm{~m}$ \\
Pitch radius of gyration $\left(\mathrm{r}_{55}\right)$ & $39.24 \mathrm{~m}$ \\
Roll radius of gyration $\left(\mathrm{r}_{44}\right)$ & $13.36 \mathrm{~m}$ \\
Yaw radius of gyration $\left(\mathrm{r}_{66}\right)$ & $40.88 \mathrm{~m}$ \\
Design speed $(\mathrm{U})$ & $20 \mathrm{knots}$ \\
\hline
\end{tabular}

The Marintek Catamaran is taken as a ship model and has been scaled to real ship dimensions. All details related to the catamaran model can be found in Hermundstad et al. (1999).

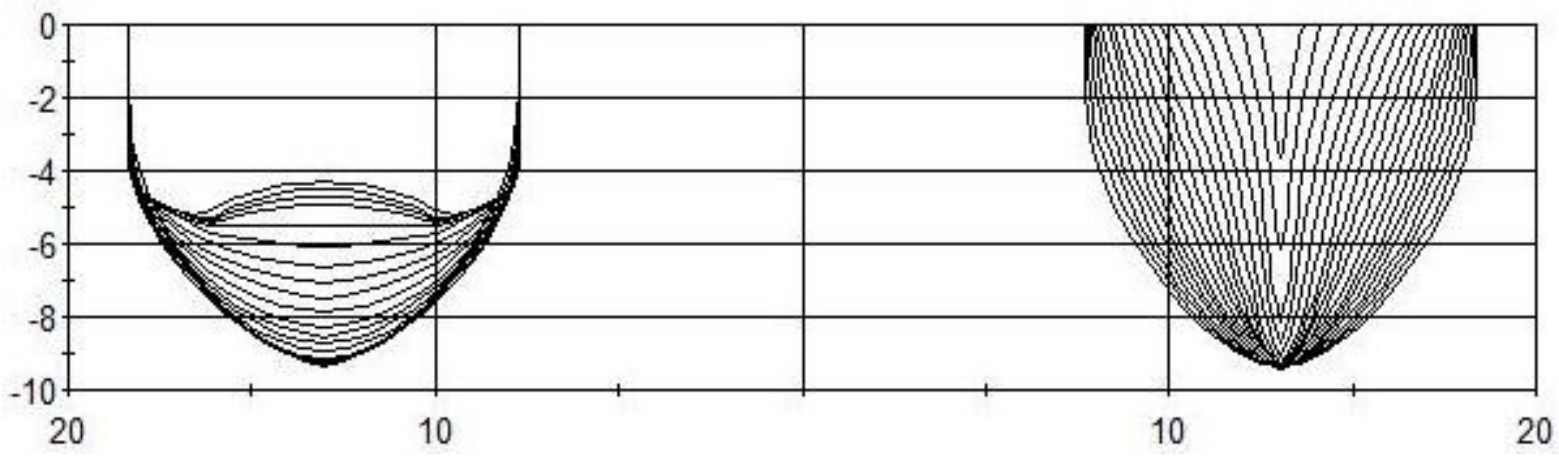

Figure 4. Sections of a demihull

(left and right hand sides of the graph show aft and forward stations, respectively).

Although the demi-hulls of the catamaran geometry are connected to each other above the water line, only the sections under the free surface have been shown in Figure 4.

All of the necessary stages to predict the operability of the vessel are briefly explained in the following sub-sections. 


\subsection{Ship responses to regular waves}

Typically, the first stage in the assessment of a ship's operability is to predict the ship response characteristics in regular waves for a range of headings and ship speeds in the frequency domain. The transfer functions (RAOs) are usually calculated due to either a unit wave amplitude elevation for translational motions, or a unit wave slope amplitude for angular motions.

The numerical RAOs of the ferry, obtained by using each theory, are compared to the experimental data published by Hermundstad et al. (1999). Four different combinations of ship speed and wave heading are presented below, being identified by their case numbers.

- Case 1: Froude number 0.47 (corresponds to a forward speed of 35.18 knots). Head seas.

- Case 2: Froude number 0.63 (corresponds to a forward speed of 47.16 knots). Head seas.

- Case 3: Froude number 0.63. Bow seas $\left(\beta=30^{\circ}\right)$.

- Case 4: Froude number 0.47. Beam seas $\left(\beta=90^{\circ}\right)$.

The comparisons are shown in Figures 5-8, representing the experimental results using triangles. Heave responses are non-dimensionalised by wave amplitude (A), whereas pitch and roll responses are non-dimensionalised by wave amplitude over ship length $\left(\mathrm{A} / \mathrm{L}_{\mathrm{BP}}\right)$. It is worth noting that the angular responses are given in radians. The graphs, demonstrated in Figures 5-8, are all plotted against non-dimensional wave frequency, $\omega^{\prime}=\omega\left(\mathrm{L}_{\mathrm{BP}} / \mathrm{g}\right)^{1 / 2}$.
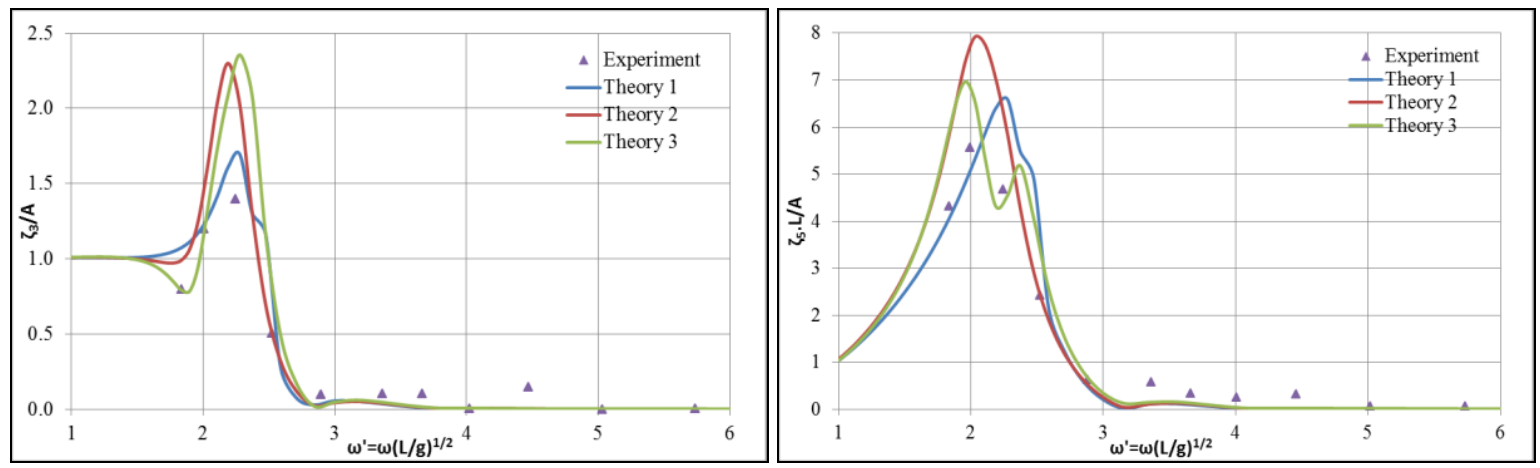

Figure 5. Experimental and numerical RAOs for Case 1. Left and right hand sides of the graph show heave and pitch RAOs, respectively.
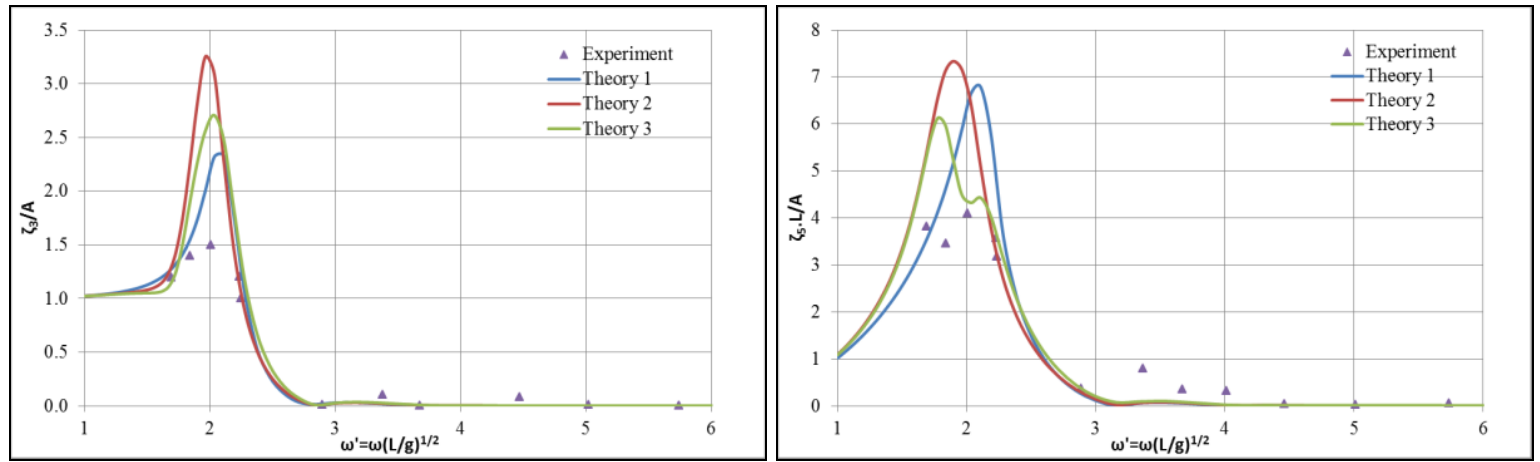

Figure 6. Experimental and numerical RAOs for Case 2. Left and right hand sides of the graph show heave and pitch RAOs, respectively. 

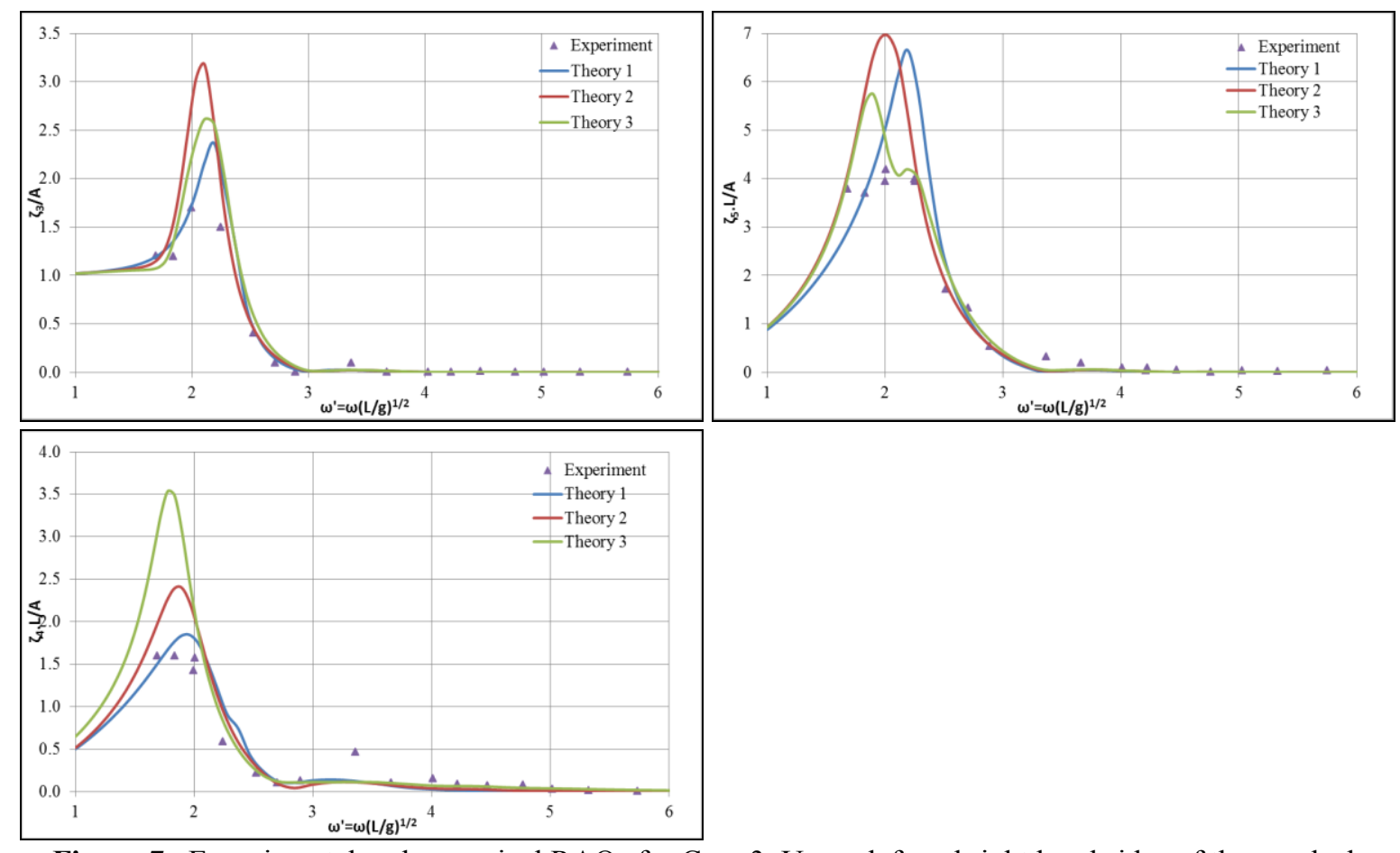

Figure 7. Experimental and numerical RAOs for Case 3. Upper left and right hand sides of the graph show heave and pitch RAOs, respectively. Lower part shows roll RAOs.
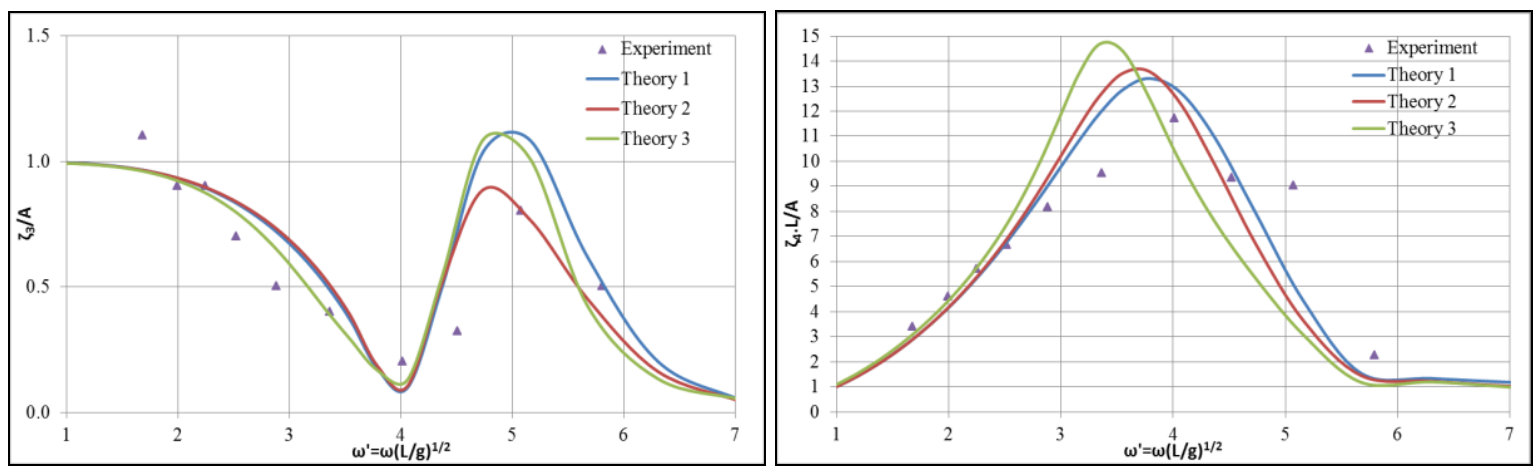

Figure 8. Experimental and numerical RAOs for Case 4. Left and right hand sides of the graph show heave and roll RAOs, respectively.

Figures 5-8 appear to demonstrate the discrepancies between each numerical technique and the experimental results. If Theory 2 is compared to Theory 3, it is evident from Figures 6 and 7 that the numerical calculation of the resonant heave motion is improved when hull interactions are taken into account. In most cases, Theory 3 shows better agreement with the experimental data relative to Theory 2 . This applies to both head and bow seas. It is worth noting that hull interactions are more dominant in heave motion compared to pitch motion at two high speeds. Conversely, for the roll motions, the discrepancies are much larger when hull interactions are taken into consideration. In most cases, of the three theories, conventional strip theory (Theory 1) is still the most compatible with the experiments, as this shows consistency with the ITTC (1987)'s conclusion, explained in the previous section.

Given that wave frequency equals the encounter frequency in beam seas, it is more convenient to compare the natural roll frequency of the vessel with the peak frequencies obtained by each numerical result in Figure 8 . The natural roll frequency of the vessel $\left(\omega_{\text {roll }}=0.96 \mathrm{rad} / \mathrm{sec}\right)$, which coincides with $\omega_{\text {roll }}^{\prime}=3.77$, is very close to the peak frequency estimated by both Theory 1 and $2\left(\omega_{\mathrm{p}}^{\prime}=3.79\right)$, followed by Theory $3\left(\omega_{\mathrm{p}}^{\prime}=3.34\right)$ in beam seas. 
Furthermore, the effects of three-dimensional flow, viscosity and nonlinearities are neglected in all three methods. This therefore causes an increase in the discrepancies between the numerical analyses and experiments (Hermundstad et al., 1999).

The sensitivity of the expected operability by using different theories to generate RAOs will be explored in the next section.

Additionally, a comparison of the vertical accelerations at the centre of gravity (CG) by means of the different theories in head seas at 20 knots ship speed $(\mathrm{Fn}=0.267)$ is given in Figure 9. The abscissa of the figure is encounter frequency, whereas the ordinate is vertical acceleration, non-dimensionalised by $\mathrm{gA} / \mathrm{L}_{\mathrm{BP}}$, conforming with the ITTC guideline (ITTC, 2011).

Figure 9 clearly demonstrates discrepancies between the vertical accelerations using different theories, particularly when applied to the resonance heave frequency (natural heave frequency of the vessel $\omega_{\text {heave }}=1.184 \mathrm{rad} / \mathrm{sec}$ ). The RAO vertical acceleration calculated using Theory 3 is 4.18 and 2.18 times higher than that obtained by Theory 1 and 2 in the resonance frequency, respectively. Vertical acceleration by means of Theory 3 gives higher results because of the effect of wave interactions between each demihull. This will be discussed in detail in the following paragraphs. If Theory 1 is compared to Theory 2 , the differences in the vertical acceleration around the resonance frequency arise from the evaluation of forward speed in the free surface condition.

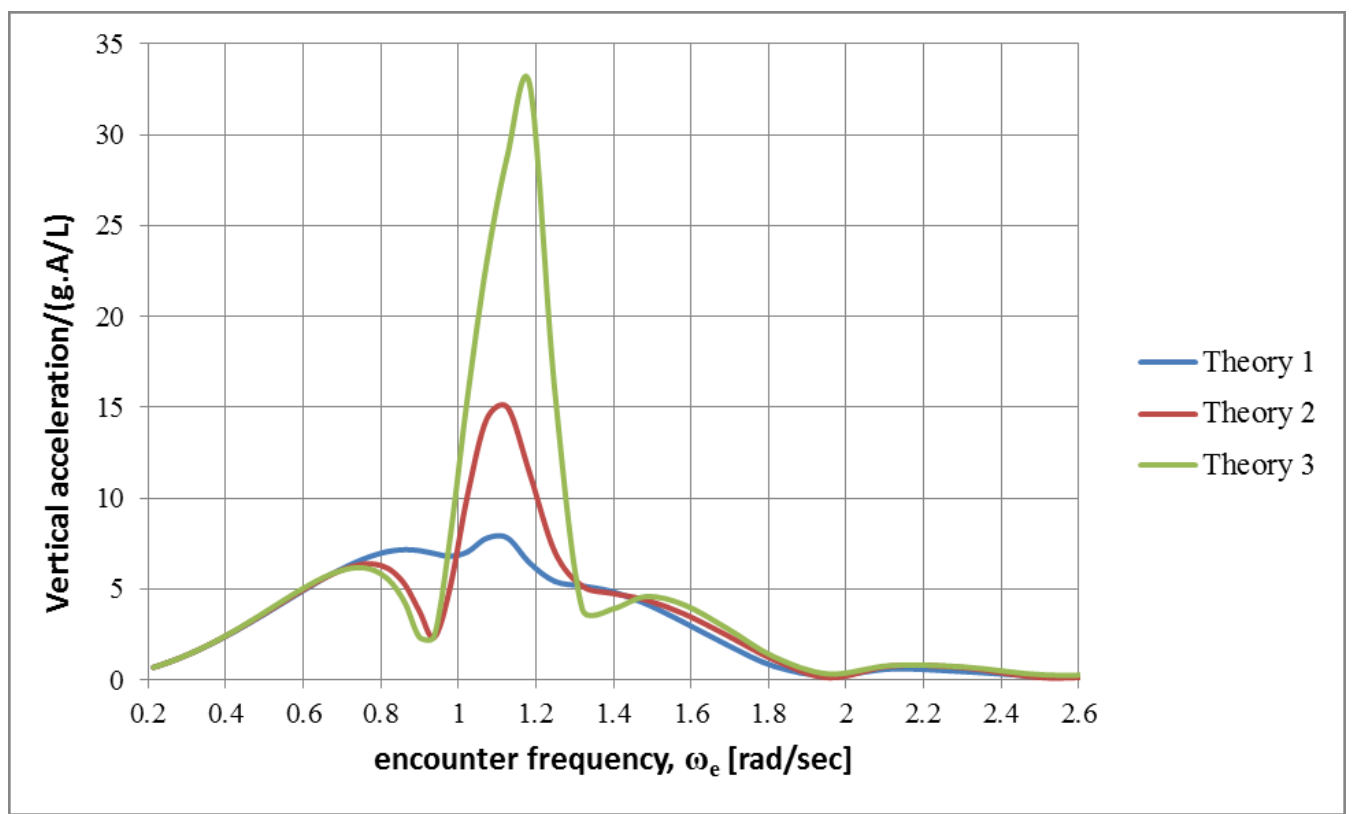

Figure 9. Vertical acceleration RAOs at the centre of gravity against encounter frequency in head seas at 20 knots speed.

Typical vertical acceleration RAOs in head seas as a function of wave frequency and ship service speed, calculated using Theory 1, 2 and 3, are shown in Figures 10-12, respectively. 


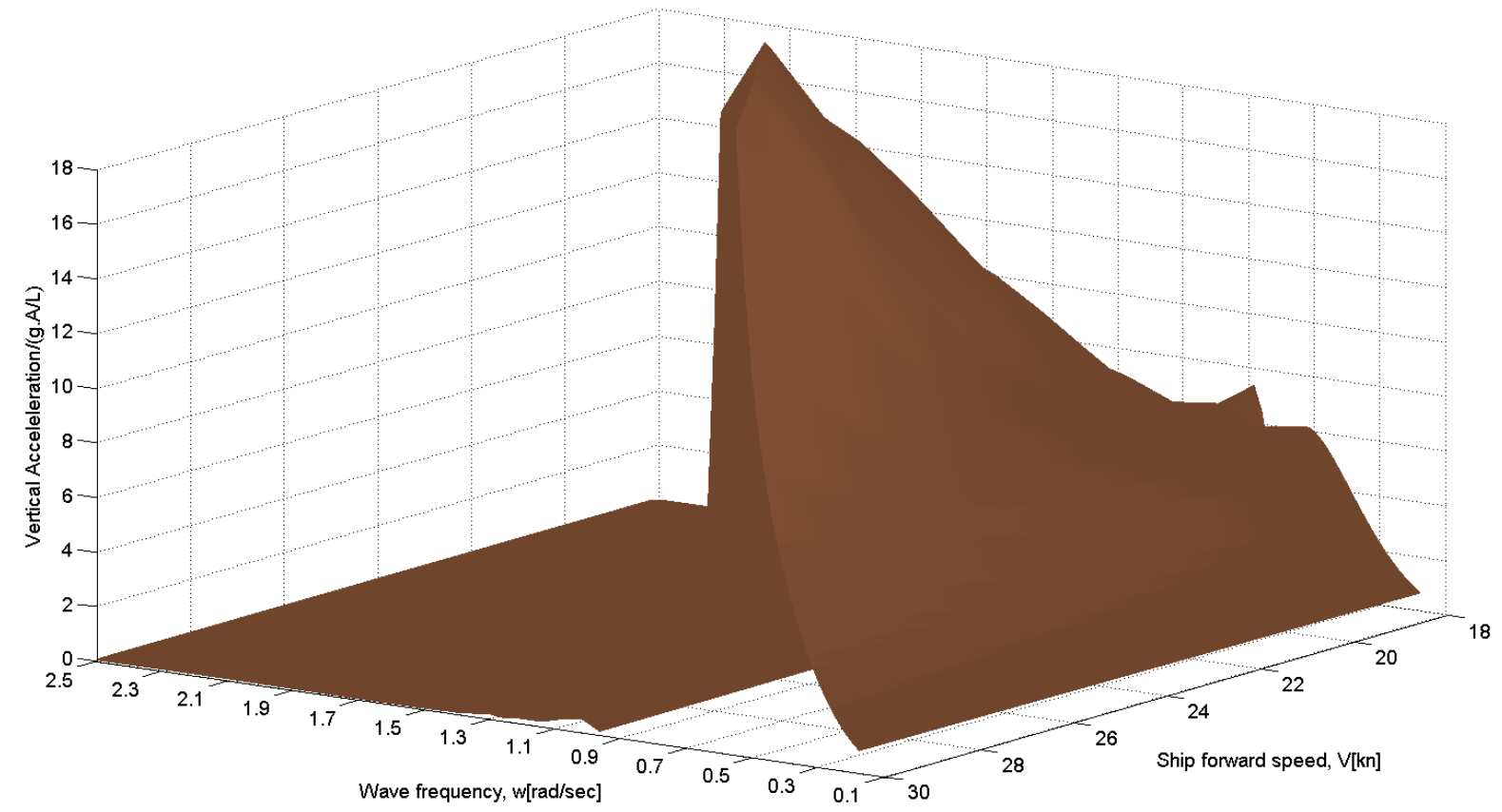

Figure 10. Vertical acceleration RAOs at the centre of gravity in head seas, calculated using Theory 1 at a range of forward speeds.

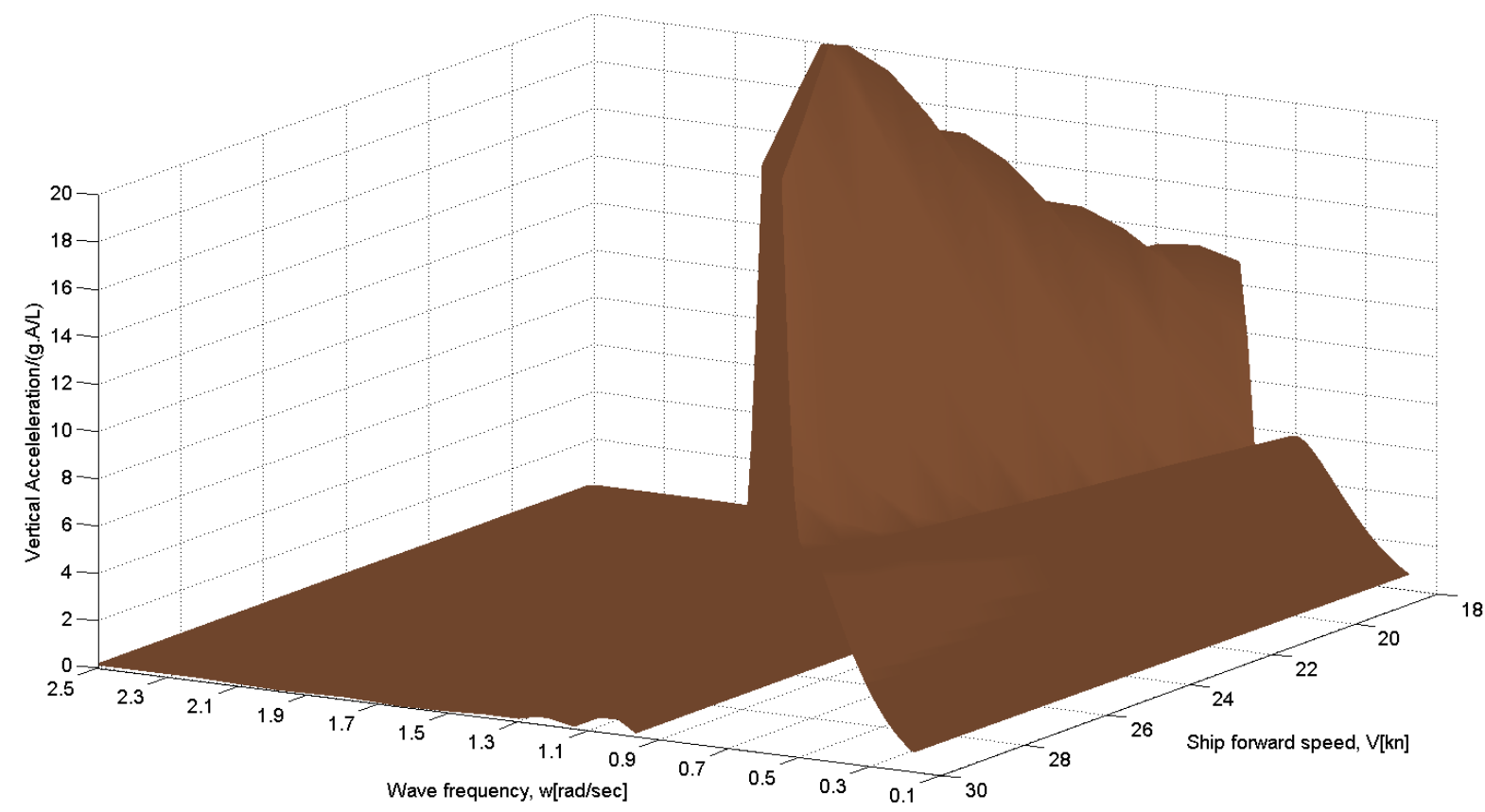

Figure 11. Vertical acceleration RAOs at the centre of gravity in head seas, calculated using Theory 2 at a range of forward speeds. 


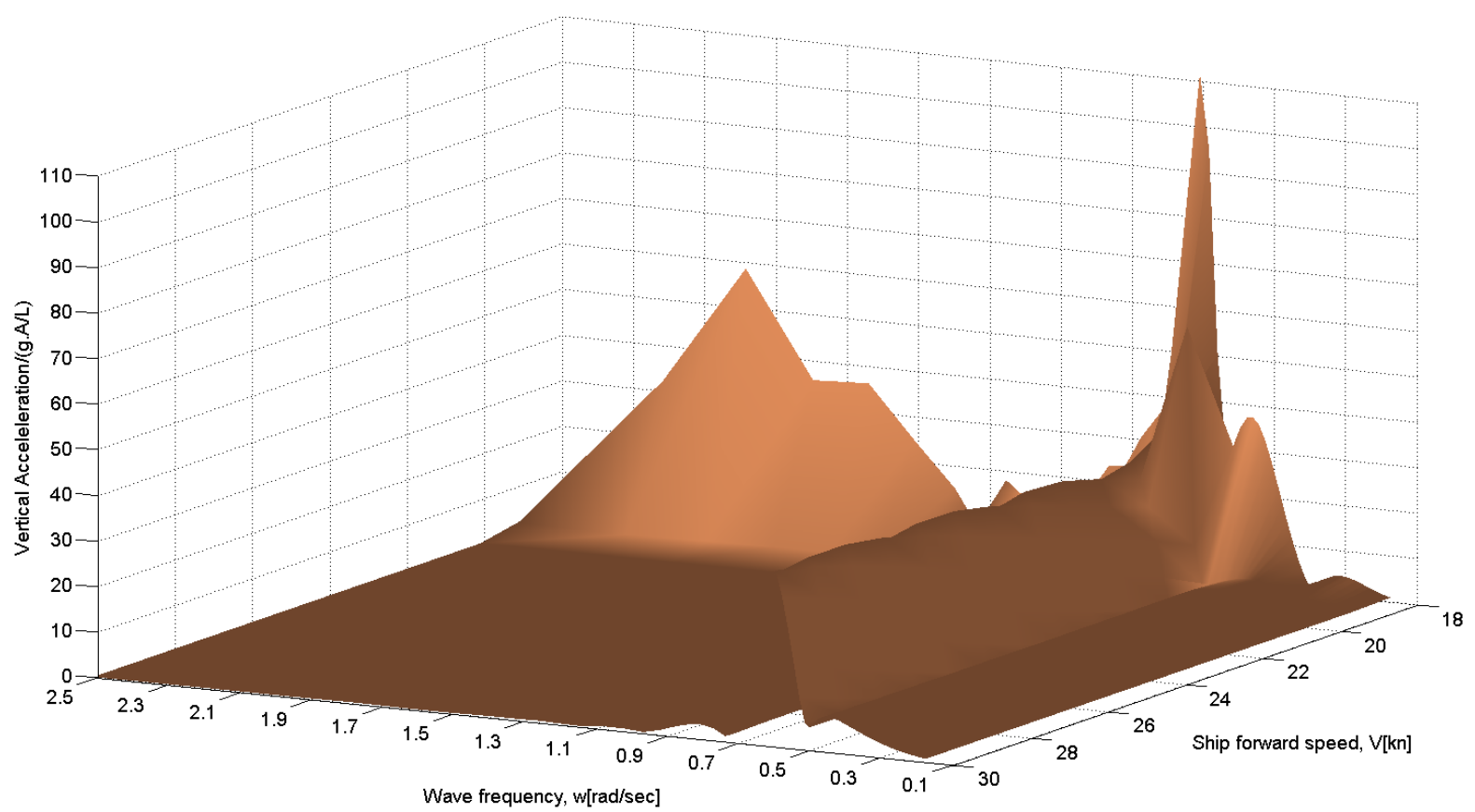

Figure 12. Vertical acceleration RAOs at the centre of gravity in head seas, calculated using Theory 3 at a range of forward speeds.

Figures 10-12 demonstrate that vertical acceleration RAOs obtained using Theory 1 and 2 are very similar to each other, showing a gradual increase with increasing speed. Conversely, vertical accelerations generated using Theory 3 (Figure 12) show a different trend. They decrease with increasing speed between a speed range of 18-21 knots, and after this particular range they gradually increase with increasing speed, showing an expected trend. This is due to the fact that hydrodynamic hull interactions are most significant within a speed range of 18-21 knots for the ferry in question, and the waves generated by each demihull affect the vertical accelerations. According to Eq. 2, for a given frequency of encounter, the wave interaction between demihulls decreases as ship speed increases. This clearly explains why the vertical accelerations obtained using Theory 3 show a reversed trend between this particular speed range.

Table 2 presents $L_{1} / L$ ratios (based on Eq. 2) against a range of wave frequencies, for varying forward speeds of the ferry.

Table 2. $\mathrm{L}_{1} / \mathrm{L}$ ratios of the ferry, calculated based on Eq. 2, for a range of $\omega$ at different speeds.

\begin{tabular}{|c|c|c|c|c|c|c|c|c|c|c|c|c|c|}
\hline \multirow{2}{*}{$\begin{array}{c}\omega \\
(\mathrm{rad} / \mathrm{s})\end{array}$} & \multicolumn{10}{|c|}{ Ship forward speed, U (knots) } \\
\cline { 2 - 15 } & $\mathbf{1 8}$ & $\mathbf{1 9}$ & $\mathbf{2 0}$ & $\mathbf{2 1}$ & $\mathbf{2 2}$ & $\mathbf{2 3}$ & $\mathbf{2 4}$ & $\mathbf{2 5}$ & $\mathbf{2 6}$ & $\mathbf{2 7}$ & $\mathbf{2 8}$ & $\mathbf{2 9}$ & $\mathbf{3 0}$ \\
\hline $\mathbf{0 . 1}$ & 0.97 & 0.97 & 0.97 & 0.97 & 0.97 & 0.96 & 0.96 & 0.96 & 0.96 & 0.96 & 0.95 & 0.95 & 0.95 \\
\hline $\mathbf{0 . 2}$ & 0.94 & 0.93 & 0.93 & 0.93 & 0.92 & 0.92 & 0.91 & 0.91 & 0.91 & 0.90 & 0.90 & 0.89 & 0.89 \\
\hline $\mathbf{0 . 4}$ & 0.86 & 0.85 & 0.84 & 0.83 & 0.82 & 0.80 & 0.79 & 0.78 & 0.77 & 0.76 & 0.75 & 0.73 & 0.72 \\
\hline $\mathbf{0 . 6}$ & 0.76 & 0.74 & 0.72 & 0.70 & 0.68 & 0.66 & 0.64 & 0.62 & 0.59 & 0.57 & 0.55 & 0.52 & 0.50 \\
\hline $\mathbf{0 . 8}$ & 0.64 & 0.61 & 0.58 & 0.55 & 0.51 & 0.48 & 0.45 & 0.41 & 0.38 & 0.34 & 0.30 & 0.26 & 0.22 \\
\hline $\mathbf{1 . 0}$ & 0.50 & 0.46 & 0.41 & 0.37 & 0.32 & 0.27 & 0.22 & 0.17 & 0.12 & 0.06 & 0.01 & {[]} & {[]} \\
\hline $\mathbf{1 . 2}$ & 0.34 & 0.28 & 0.22 & 0.16 & 0.10 & 0.03 & {[]} & {[]} & {[]} & {[]} & {[]} & {[]} & {[]} \\
\hline $\mathbf{1 . 4}$ & 0.16 & 0.08 & 0.01 & {[]} & {[]} & {[]} & {[]} & {[]} & {[]} & {[]} & {[]} & {[]} & {[]} \\
\hline
\end{tabular}

Empty brackets [ ] indicate that there is no applicable hull interaction. Table 2 shows that the length $\mathrm{L}_{1}$ decreases as the wave frequency increases, in other words the $\mathrm{L}_{1} / \mathrm{L}$ ratio decreases 
with decreasing wavelength. It is evident that the hull interaction is most significant in low encounter frequencies at relatively lower ship speeds.

\subsection{Ship responses to irregular waves}

The real seaways can only be modelled by virtue of a statistical model. Ship responses to natural irregular seas $\left(S_{z}\right)$ are calculated by the linear superposition principle, using the seaway spectrum $\left(\mathrm{S}_{\zeta}\right)$ and the transfer functions in the frequency domain as given below.

$$
S_{z}(\omega)=S_{\zeta}(\omega)|R A O(\omega)|^{2}
$$

Several spectral formulations are available in the literature. One of the most frequently used spectrums is the JONSWAP spectrum, which was developed in 1973 by the Joint North Sea Wave Project and described by Hasselmann et al. (1973). The JONSWAP formulation has been adopted for the fetch limited North Sea and can be expressed as follows:

$$
S_{\zeta}(\omega)=\left[\frac{\alpha g^{2}}{\omega^{5}} \cdot \exp \left\{-\frac{5}{4}\left(\frac{\omega_{p}}{\omega}\right)^{4}\right\} \cdot \gamma^{\exp \left\{\frac{\left(\omega-\omega_{p}\right)^{2}}{2 \sigma^{2} \omega_{p}^{2}}\right\}}\right.
$$

where $\omega$ and $\omega_{\mathrm{p}}$ are the incident wave and modal wave periods, respectively. $\sigma$ represents the spectral width parameter and is calculated according to the following expression:

$$
\sigma= \begin{cases}0.07 & \omega \leq \omega_{p} \\ 0.09 & \omega>\omega_{p}\end{cases}
$$

$\gamma$ refers to the peak-enhancement factor and is generally taken to be 3.30. $\alpha$ is the normalisation factor, given by

$$
\alpha=5.061(2 \pi)^{-4} H_{s}^{2} \omega_{p}^{4}[1-0.287 \ln (\gamma)]
$$

The JONSWAP parametric spectrum is chosen for this study. The spectral density distribution of the spectrum for $\mathrm{H}_{\mathrm{s}}=3.5 \mathrm{~m}$ is illustrated in Figure 13.

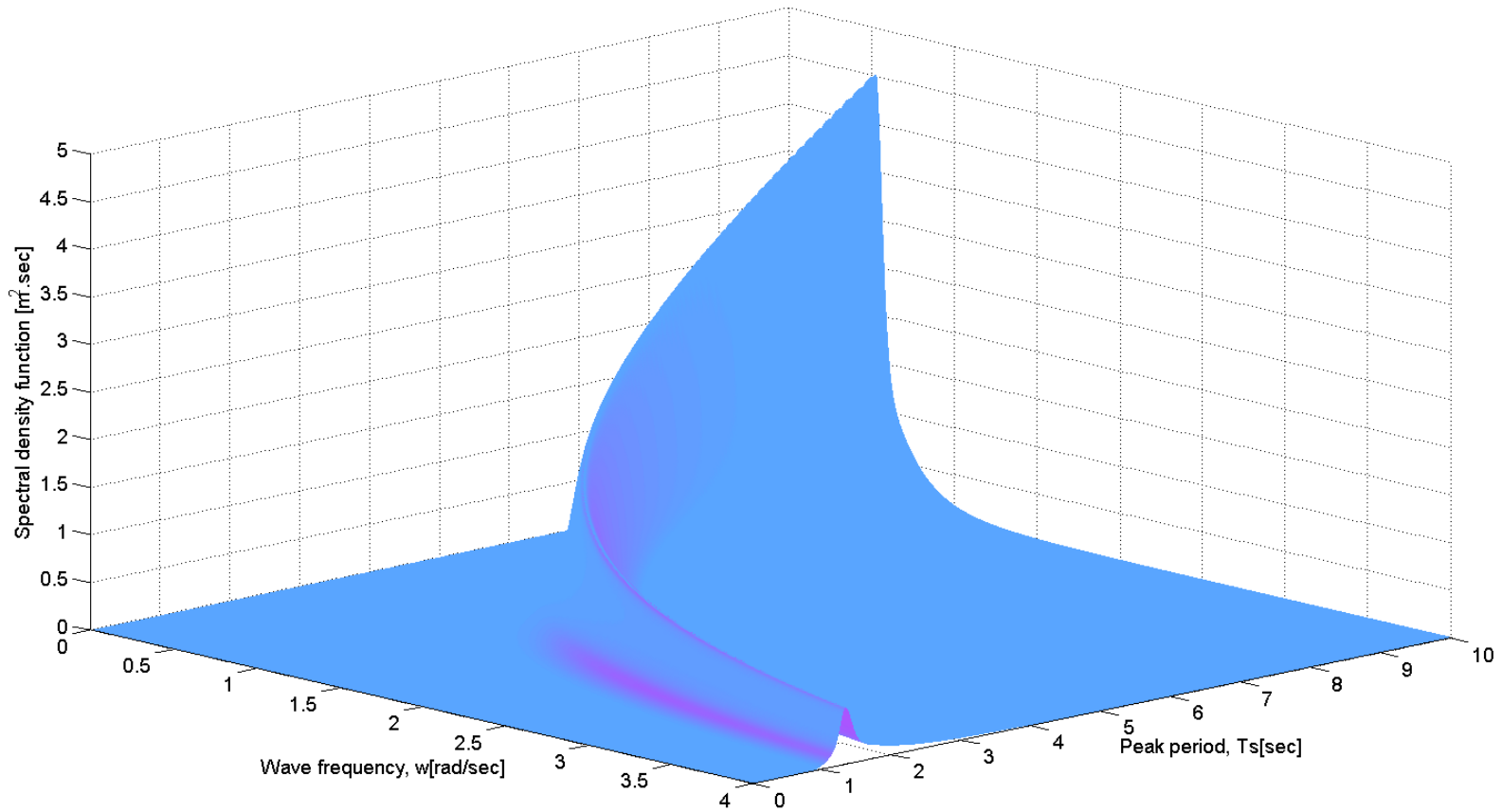

Figure 13. Spectral density distribution of the JONSWAP spectrum for $\mathrm{H}_{\mathrm{s}}=3.5 \mathrm{~m}$. 
The response spectrum $S_{z}(\omega)$ is the product of the defined sea spectrum $S_{\zeta}(\omega)$ and square of the transfer function $\mathrm{RAO}^{2}(\omega)$ as given in Eq. 3. Once the response spectrum is obtained, all statistical values of the response are derived by using the spectral technique.

The variance of the response spectrum is the area under the spectrum curve with respect to natural wave frequency and can be shown by:

$m_{0}=\int_{0}^{\infty} S_{z}(\omega) d \omega$

The square root of Eq. 6 gives the root mean square (RMS) of the response, which describes the most frequently observed amplitude of the waves or responses.

$x_{R M S}=\sqrt{m_{0}}$

in which $\mathrm{m}_{0}$ is the zeroth spectral moment. Principally, the $\mathrm{n}^{\text {th }}$ order spectral moment can be presented by

$m_{n}=\int_{0}^{\infty} \omega^{n} S_{z}(\omega) d \omega$

The square roots of the $\mathrm{m}_{2}$ and $\mathrm{m}_{4}$ spectral moments correspond to RMS velocity and acceleration responses, respectively.

\subsection{Determination of the limiting significant wave heights}

Soares et al. (1995) suggest that the wave spectrum can be represented as the product of the normalised wave spectrum in terms of the significant wave height $S_{\zeta_{1}}(\omega)$ and square of the significant wave height $\mathrm{H}_{\mathrm{s}}$ due to the linearity assumption.

$S_{\zeta}\left(\omega, H_{s}, T_{s}\right)=H_{s}^{2} S_{\zeta}\left(\omega, 1, T_{s}\right)=H_{s}^{2} S_{\zeta 1}\left(\omega, T_{s}\right)$

By analogy to equation (9), the response spectrum may also be formulated as:

$S_{z}(\omega)=H_{s}^{2} S_{z 1}(\omega)=H_{s}^{2} S_{\zeta 1}\left(\omega, T_{s}\right) R A O^{2}(\omega)$

and the variance of the response can be given by:

$m_{0}=\int_{0}^{\infty} S_{z}(\omega) d \omega=H_{s}^{2} \int_{0}^{\infty} S_{\zeta 1}\left(\omega, T_{s}\right) R A O^{2}(\omega) d \omega$

which can briefly be symbolised as follows:

$m_{0}=H_{s}^{2} m_{01}$

For cases in which a seakeeping criterion is defined as a root mean square of a response $\mathrm{x}_{\mathrm{RMS}}$, the limiting significant wave height for a specific modal wave period $T_{s}$, and ship heading $\beta$ is determined by using the following equation:

$H_{s}^{\lim }\left(T_{s}, \beta\right)=\frac{x_{R M S}^{\lim }}{x_{R M S, 1}}$

\subsection{Calculation of the operability index}

Fonseca and Soares (2002) define the operability index as "the percentage of time during which the ship is operational". The operability index is calculated according to the following common expression, which was also used in Khalid et al. (2009):

Op. $(\%)=\frac{\sum_{H_{s}, T_{s}} n_{s s, \beta}\left(H_{s}<H_{s}^{\mathrm{lim}}\right)}{N} \times 100$ 
With regards to Eq. 14 the operability index is the ratio of the number of waves (for all available zero crossing periods) with significant wave heights not exceeding the maximum significant wave height $\left(\mathrm{n}_{\mathrm{ss}, \beta}\right)$ relative to the total number of waves $(\mathrm{N})$ in the wave scatter diagram of interest.

\section{OPERABILITY ANALYSIS}

The procedure presented in the previous sections can be used to evaluate ship motions and motion-related responses to both regular waves and irregular seaways. Short term and long term statistics are obtained in irregular seas to predict the most probable maximum values of the ship responses. On the other hand, if these results are evaluated alone, they cannot properly express the performance of a ship from a seakeeping point of view. An operability index which is capable of measuring the degradation of the ship's performance to accomplish her tasks should be computed to quantify the seakeeping ability of the vessel (Fonseca and Soares, 2002).

\subsection{Selection of the limiting criteria}

In order to calculate the operability index of the ferry, the limiting criteria should be defined concerning passenger comfort and safety. A passenger ship's seakeeping performance depends partly on lateral accelerations, but mostly on vertical accelerations (Riola and Arboleya, 2006).

The influence of the vertical acceleration on human metabolism is the major reason for seasickness. Discomfort regions are determined by the International Standard as a function of acceleration levels, frequencies, and exposure times. There are some parameters to quantify the effects of accelerations on human performance on-board. They may be regarded as a good reference to compare the human performance between ship designs (Giron et al., 2001).

The International Standard ISO 2631/1 (ISO, 1997) presents an approach to measure wholebody vibration in connection with human health and comfort, relating this to the probability of vibration and motion sickness incidence.

Motion Sickness Incidence (MSI) and Motion Induced Interruptions (MII) are the two most highly referenced parameters to quantify the ship motion effects on human performance and comfort. MSI indicates the percentage of people experiencing vomiting when exposed to motion for a certain of time. It was proposed as a function of the wave frequency and vertical acceleration by O'Hanlon and McCauley (1974), following which a mathematical expression was developed by McCauley et al. (1976).

Graham (1990) developed the motion induced interruption concept, which is defined as the number of loss-of-balance events that occur during an arbitrary operation on-board. The theory, which is explained in detail in his study, is based on the calculation of the lateral force estimator (LFE) which causes objects to topple or slide, and people to lose their balance, in the frequency domain. Graham concluded that a limit on the number of MIIs can be applied as the most appropriate criterion for deck operations. Table 3 presents the proposed values in terms of different risk levels. 
Table 3. MII risk levels (Graham, 1990).

\begin{tabular}{|c|c|}
\hline Risk level & MIIs per minute \\
\hline 1. Possible & 0.1 \\
\hline 2. Probable & 0.5 \\
\hline 3. Serious & 1.5 \\
\hline 4. Severe & 3.0 \\
\hline 5. Extreme & 5.0 \\
\hline
\end{tabular}

The derived transfer functions are normally calculated with respect to specific positions on the ship which are closely associated with the limiting criteria to be used. Table 4 lists these locations on the ship and the seakeeping criteria that are selected for the operability assessment of the ferry. The locations in Table 4 are given according to $\mathrm{x}, \mathrm{y}$, and $\mathrm{z}$ coordinates, where $\mathrm{x}$ denotes the point forward after aft peak, $\mathrm{y}$ denotes the position off centre (positive starboard), and $\mathrm{z}$ denotes the location above the base line.

Table 4. Seakeeping criteria for the high speed passenger ferry.

\begin{tabular}{|l|l|l|l|l|}
\hline Description & Criterion & Location & Coordinates (m) & Reference \\
\hline $\begin{array}{l}\text { Vertical } \\
\text { acceleration }\end{array}$ & $\begin{array}{l}2 \text { hours exposure } \\
0.05 \mathrm{~g}\end{array}$ & Passenger deck & $80,0,10$ & $\begin{array}{l}\text { ISO 2631/3, } \\
1985\end{array}$ \\
\hline MII & $0.5 \mathrm{MII}$ per minute & Car deck & $150,0,11$ & $\begin{array}{l}\text { Graham, } \\
1990\end{array}$ \\
\hline MSI & $35 \%$ MSI in 2 hours & $\begin{array}{l}\text { Crew } \\
\text { accommodation }\end{array}$ & $25,-4,9.5$ & $\begin{array}{l}\text { ISO 2631/1, } \\
1997\end{array}$ \\
\hline $\begin{array}{l}\text { Lateral } \\
\text { acceleration }\end{array}$ & $0.025 \mathrm{~g}$ (RMS) & $\begin{array}{l}\text { Centre of } \\
\text { gravity }\end{array}$ & $63.72,0,13.28$ & $\begin{array}{l}\text { ISO 2631/1, } \\
1997\end{array}$ \\
\hline
\end{tabular}

\subsection{Definition of the sea spectrum and wave scatter data}

It is assumed that the car/passenger ferry provides a fast transportation service across the west coast of Scotland (Figure 14, Global Wave Area 10).

As outlined earlier on, the JONSWAP spectrum has been selected to represent the area of operation. In order to determine the long term responses of the vessel, the probability of occurrence of the sea states at the operation area is necessary. WSD provides such information as it gives a joint probability table of significant wave heights, characteristic wave periods, and the number of occurrences for a specific sea site. The statistics of ocean wave climates for the entire globe is available in Global Wave Statistics for a specific area based on instrumental, hindcasting, and visual observation methods (Hogben et al., 1986).

The operability calculations are performed using annual and seasonal WSD. Figure 15 depicts the wave scatter data of Area 10 using annual and seasonal statistics for the wave climate. The bars in the graphs demonstrate the number of waves observed in that combination of significant wave height and wave period.

According to Lloyd (1989), for ship design purposes the most common practice is to use short crested sea with a $90^{\circ}$ spreading angle, hence the problem is treated in this fashion.

Figure 16 shows the percentage of time variances of significant wave heights observed in Area 10 with regards to annual and seasonal wave statistics. 


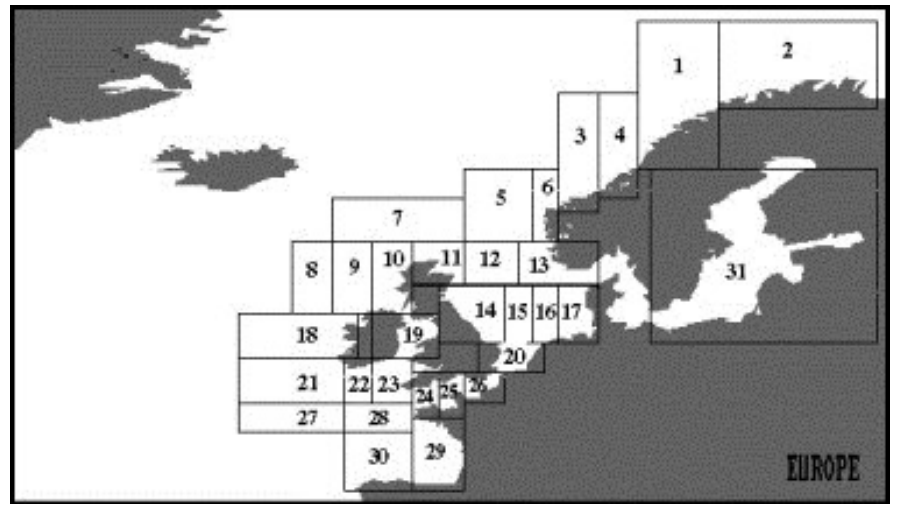

Figure 14. Global wave statistics coastal areas (Luis et al., 2009).
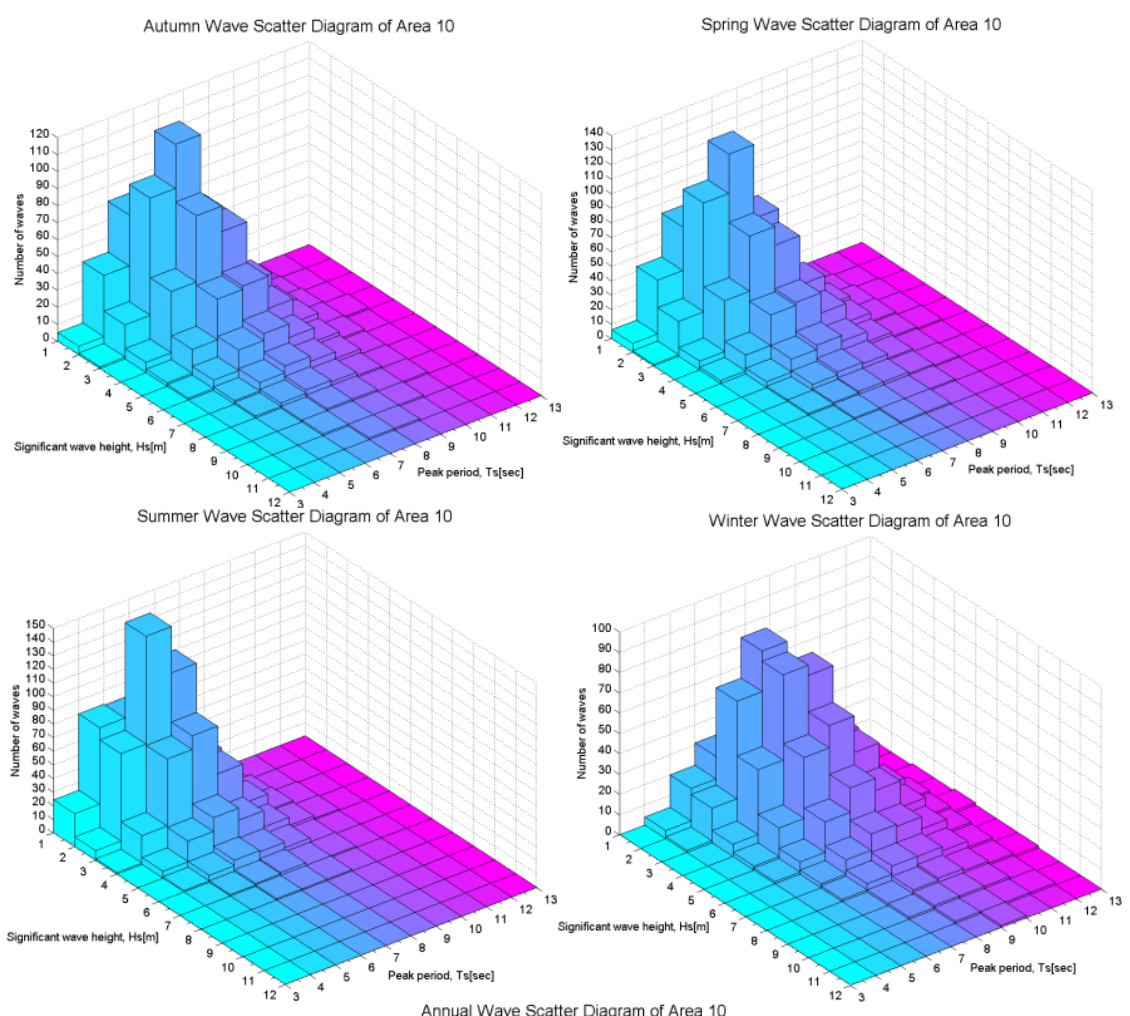

Annual Wave Scatter Diagram of Area 10

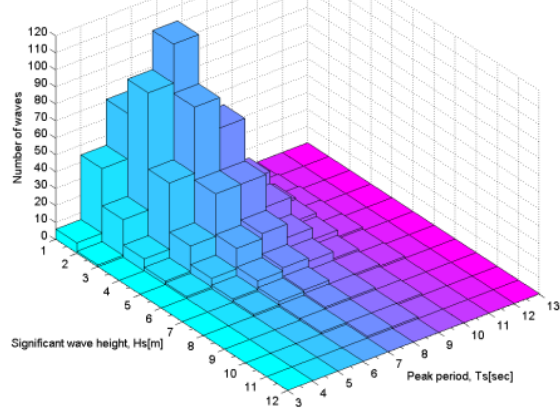

Figure 15. Wave scatter data of Area 10 regarding seasonal and annual statistics (Hogben et al., 1986). 


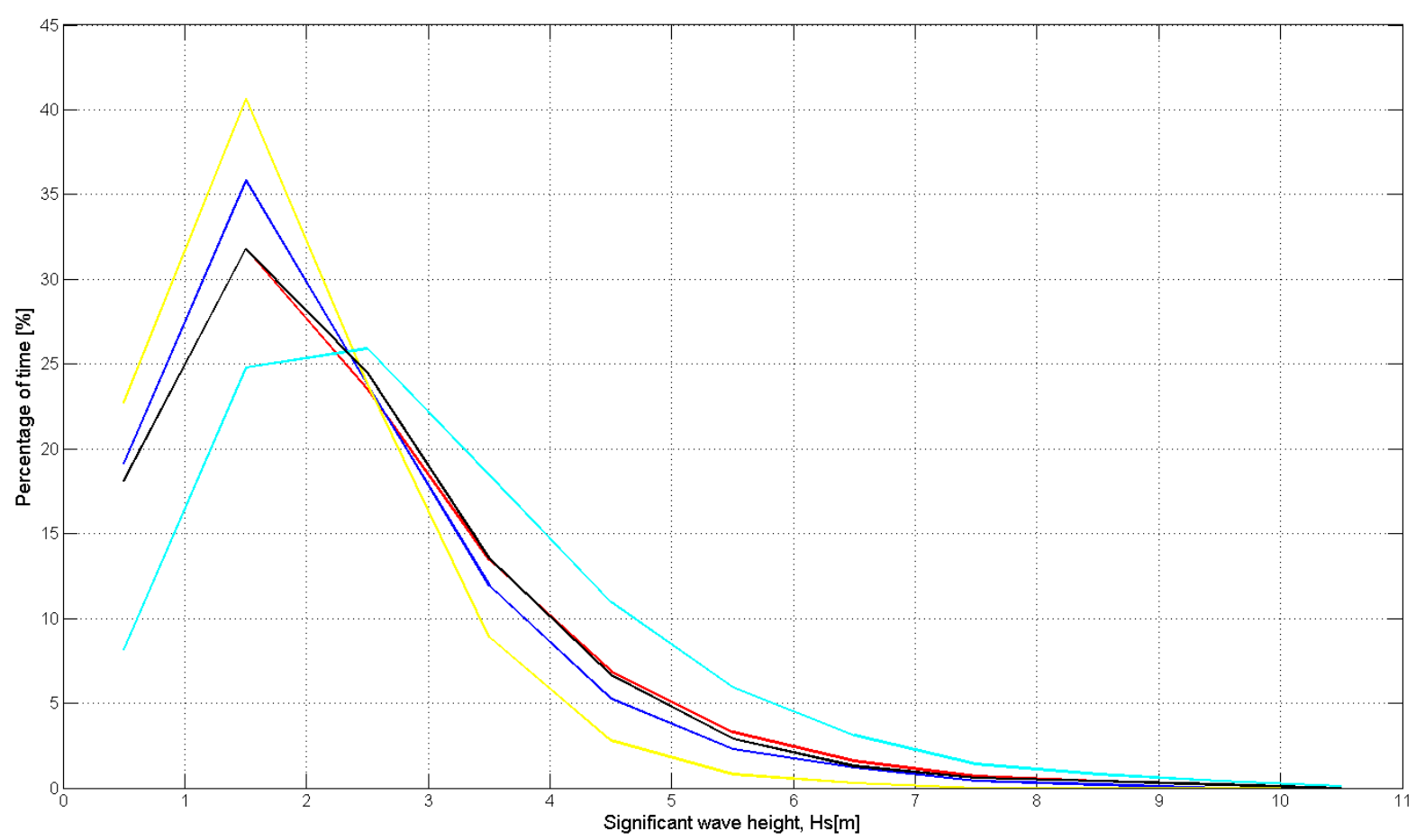

Figure 16. Percentage of time variances of significant wave heights observed in Area 10 over various durations.

\section{RESULTS}

\subsection{Motion sickness incidence}

The operability indices will be calculated in this work based on human comfort-oriented criteria. Beyond any doubt, motion sickness incidence is one of the most important criteria used to quantify human comfort due to motion in any vessel (car, train, ship). Special attention will therefore be paid to investigate MSI features of the vessel.

In this sub-section, MSI values of the ferry at the crew accommodation location will be calculated using the three different theories. MSI values are determined according to ISO 2631/1 (1997) using the following formulae:

$$
\begin{aligned}
& M S D V_{z}=\left[\int_{0}^{T} a_{w f}^{2}(t) d t\right]^{0.5}\left[m / s^{1.5}\right] \\
& M S I=K_{m} \cdot M S D V_{z}[\%]
\end{aligned}
$$

where $\mathrm{MSDV}_{\mathrm{z}}$ stands for Motion Sickness Dose Value in the vertical direction. $\mathrm{a}_{\mathrm{wf}}$ is the frequency-weighted acceleration. The integration time $\mathrm{T}$ varies between 20 min and 6 hours and is taken as 2 hours in this work. $K_{m}$ is a constant in the formula and is taken as $1 / 3$, which indicates a mixed population of unadapted male and female adults. For more information about how to predict MSI values, reference can be made to ISO 2631/1 (1997).

In order to be able to predict the MSI values of the vessel in any sea state, the statistical parameters based on the annual sea state occurrences in the open ocean Northern Hemisphere, given in Table 5, will be used. 
Table 5. Annual sea state occurrences in the open ocean Northern Hemisphere (Bales, 1982)

\begin{tabular}{lllll}
\hline $\begin{array}{l}\text { Sea State } \\
\text { No }\end{array}$ & $\begin{array}{l}\text { Significant } \\
\text { wave } \\
\text { heights } \\
\text { [metres] }\end{array}$ & $\begin{array}{l}\text { Sustained } \\
\text { wind speed } \\
\text { [knots] }\end{array}$ & $\begin{array}{l}\text { Modal wave } \\
\text { period } \\
\text { [seconds] }\end{array}$ & $\begin{array}{l}\text { Percentage } \\
\text { probability } \\
\text { of sea state }\end{array}$ \\
\hline $\mathbf{2}$ & 0.30 & 8.5 & 7 & 5.7 \\
$\mathbf{3}$ & 0.88 & 13.5 & 8 & 19.7 \\
$\mathbf{4}$ & 1.88 & 19.0 & 9 & 28.3 \\
$\mathbf{5}$ & 3.25 & 24.5 & 10 & 19.5 \\
$\mathbf{6}$ & 5.00 & 37.5 & 12 & 17.5 \\
$\mathbf{7}$ & 7.50 & 51.5 & 14 & 7.6 \\
\hline
\end{tabular}

According to the data presented in Table 5, sea state 4 is the most frequently seen sea state, with a probability of $28.3 \%$. On the other hand, sea states 2 and 7 are the least frequently observed sea states in this geographic area of interest, with probabilities of $5.7 \%$ and $7.6 \%$, respectively.

The MSI values of the ferry are predicted for various sea states at a ship speed of 20 knots. The significant wave height and modal wave period data, used in the JONSWAP spectrum, are shown in Table 5. The calculated MSI values using each theory are compared in Figure 17.

Figure 17 demonstrates the differences in MSI values using each theory. Higher sea states cause higher MSI values, as clearly seen in the figure. Also, it is evident that in the low sea states (sea states 2-4), the MSI results from each theory appear similar to each other, however in the high sea states, the discrepancies become significant. Theory 3 gives the highest results, whereas Theory 1 gives the lowest result in the high sea states. This is as expected since the vertical accelerations at 20 knots ship speed demonstrate the same trend, as shown in Figure 9.

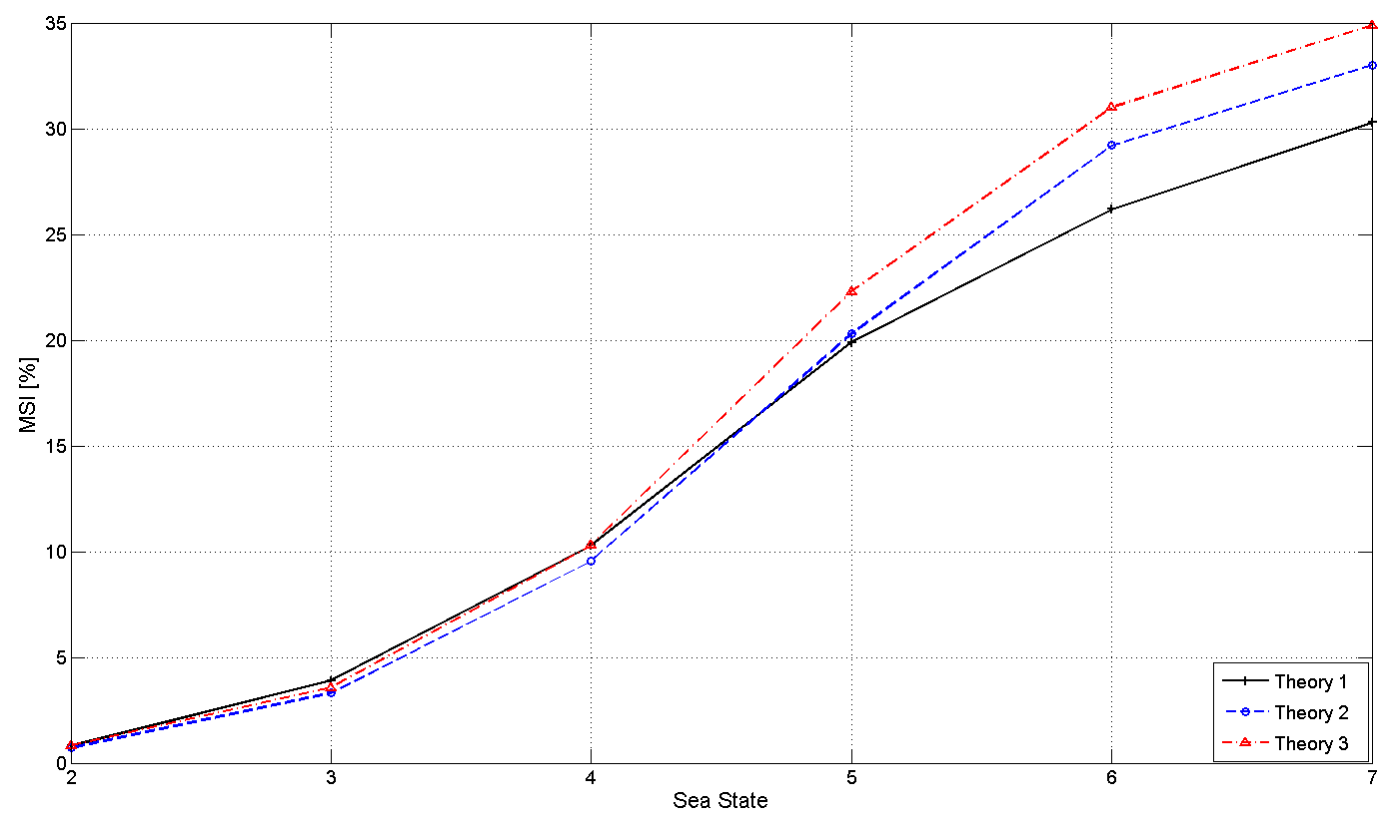

Figure 17. Motion sickness incidences calculated using each theory for varying sea states. 


\subsection{Limiting significant wave heights}

The methodology presented in the third section is applied to the ferry to measure the seakeeping performance of the vessel in terms of its operability index. All calculations have been carried out at a forward speed of 20 knots.

The limiting significant wave heights are calculated based on each criterion as a function of peak wave periods for a range of wave headings using Theory 1, 2, and 3 independently. The results are displayed in Figures 18-20, respectively.

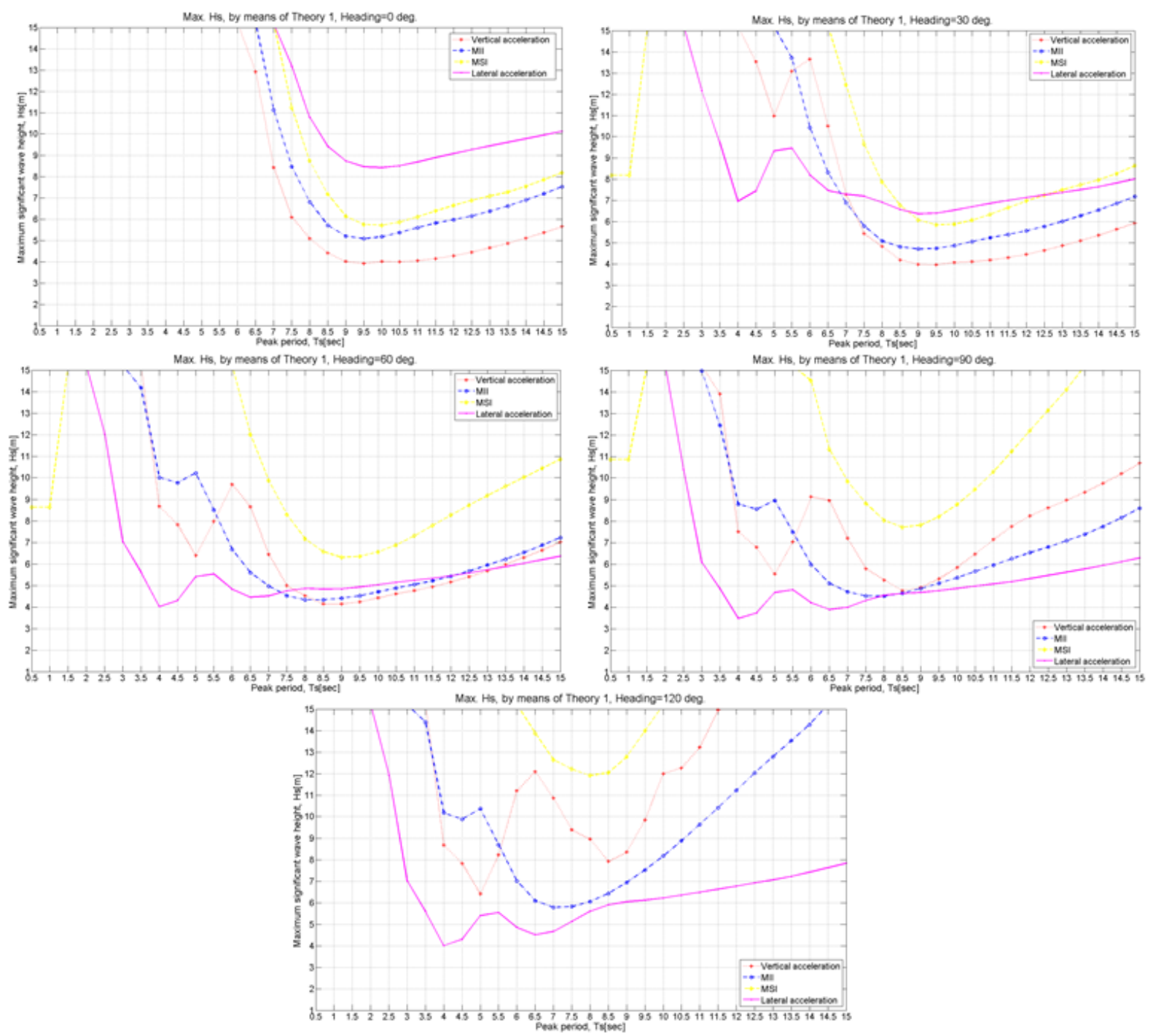

Figure 18. Limiting significant wave heights calculated using Theory 1 for various wave headings. 

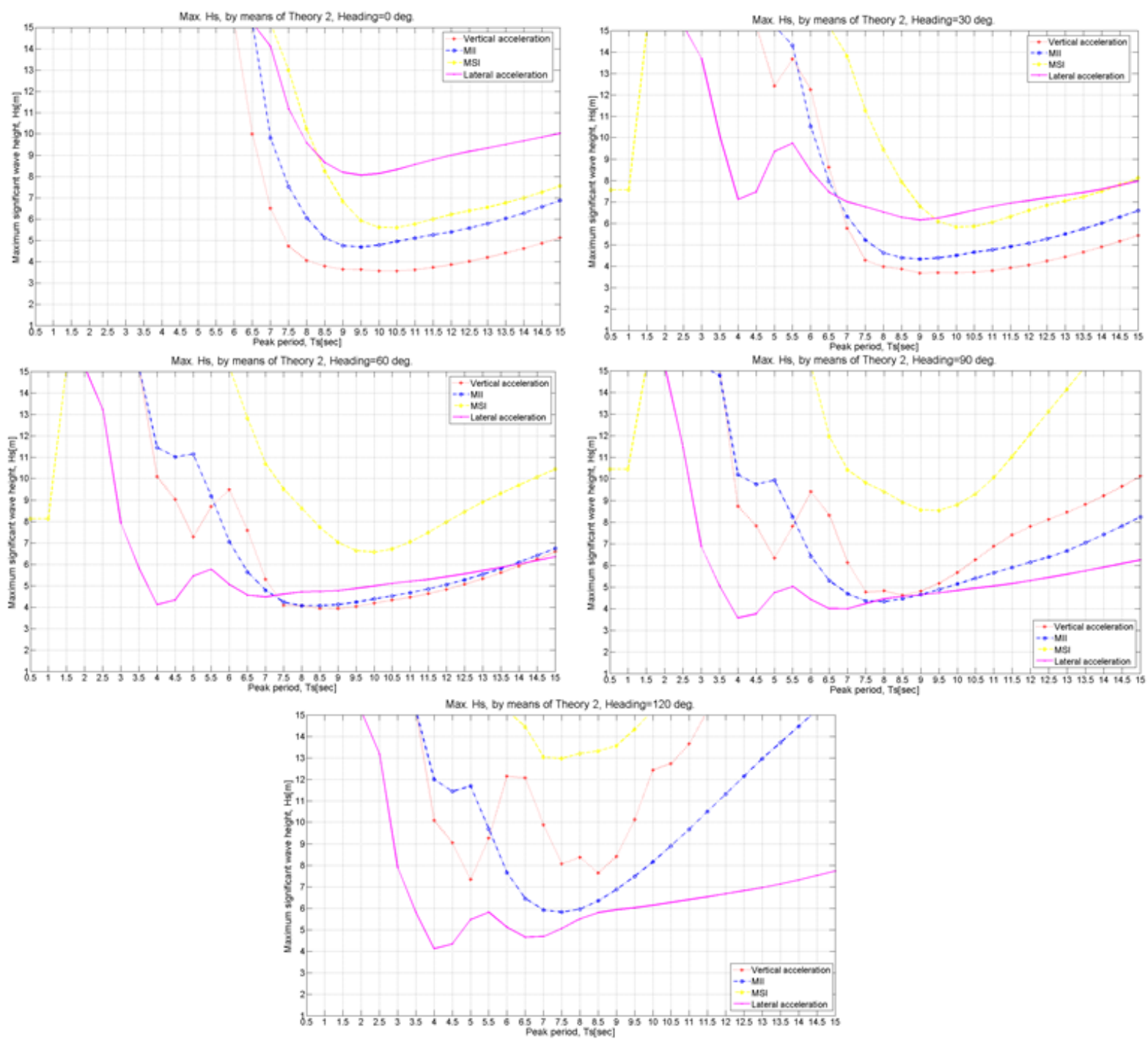

Figure 19. Limiting significant wave heights calculated using Theory 2 for various wave headings. 

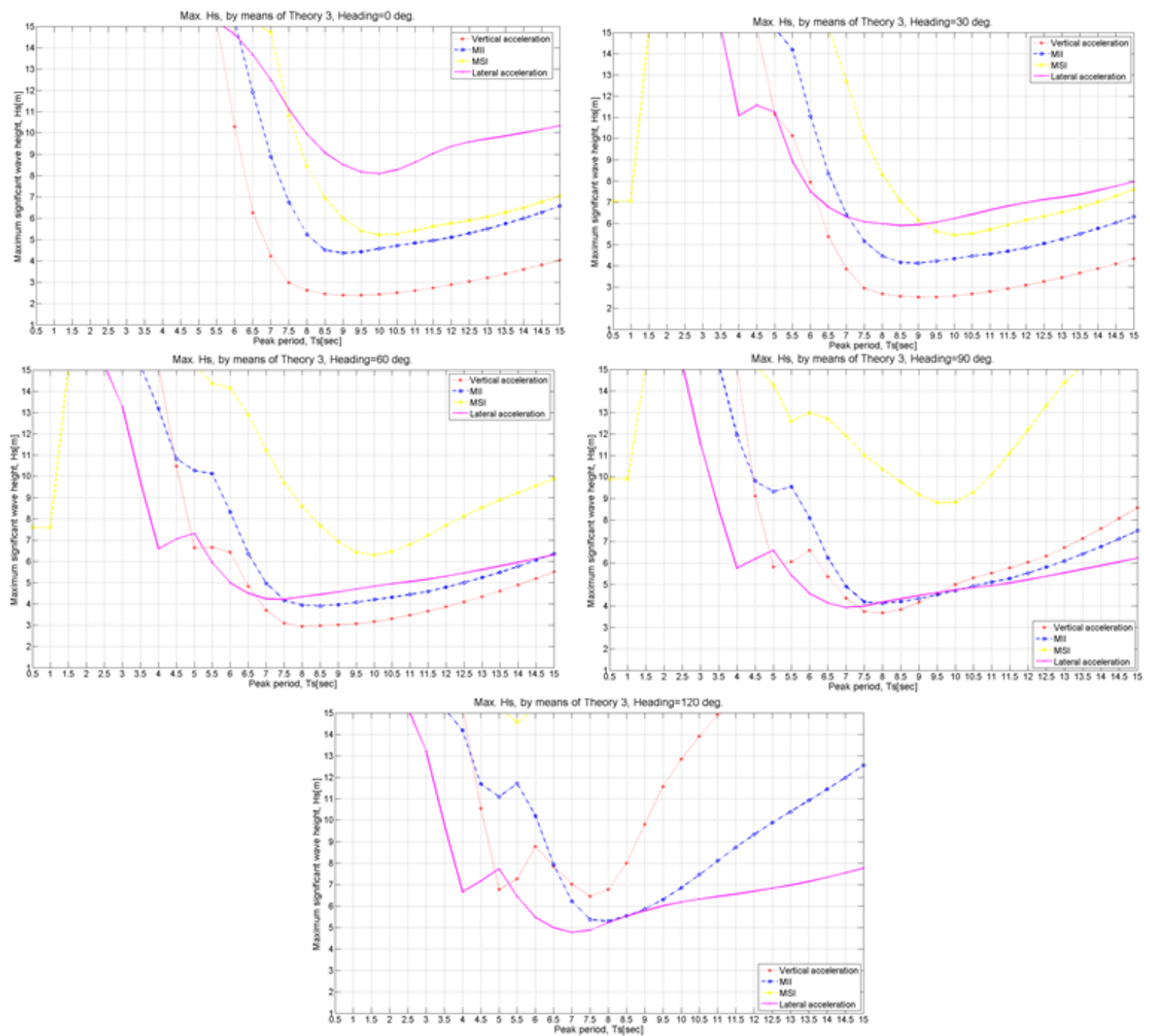

Figure 20. Limiting significant wave heights calculated using Theory 3 for various wave headings.

A comparison of the limiting significant wave heights in head seas for each criterion is displayed in Figure 21. This clearly illustrates the influence of the employed theories on the maximum allowed significant wave heights. It is seen from the figure that the differences in the limiting significant wave heights obtained using each theory are most pronounced in the vertical acceleration criterion. This will lead to noticeable discrepancies in the resultant operability indices due to vertical acceleration. 

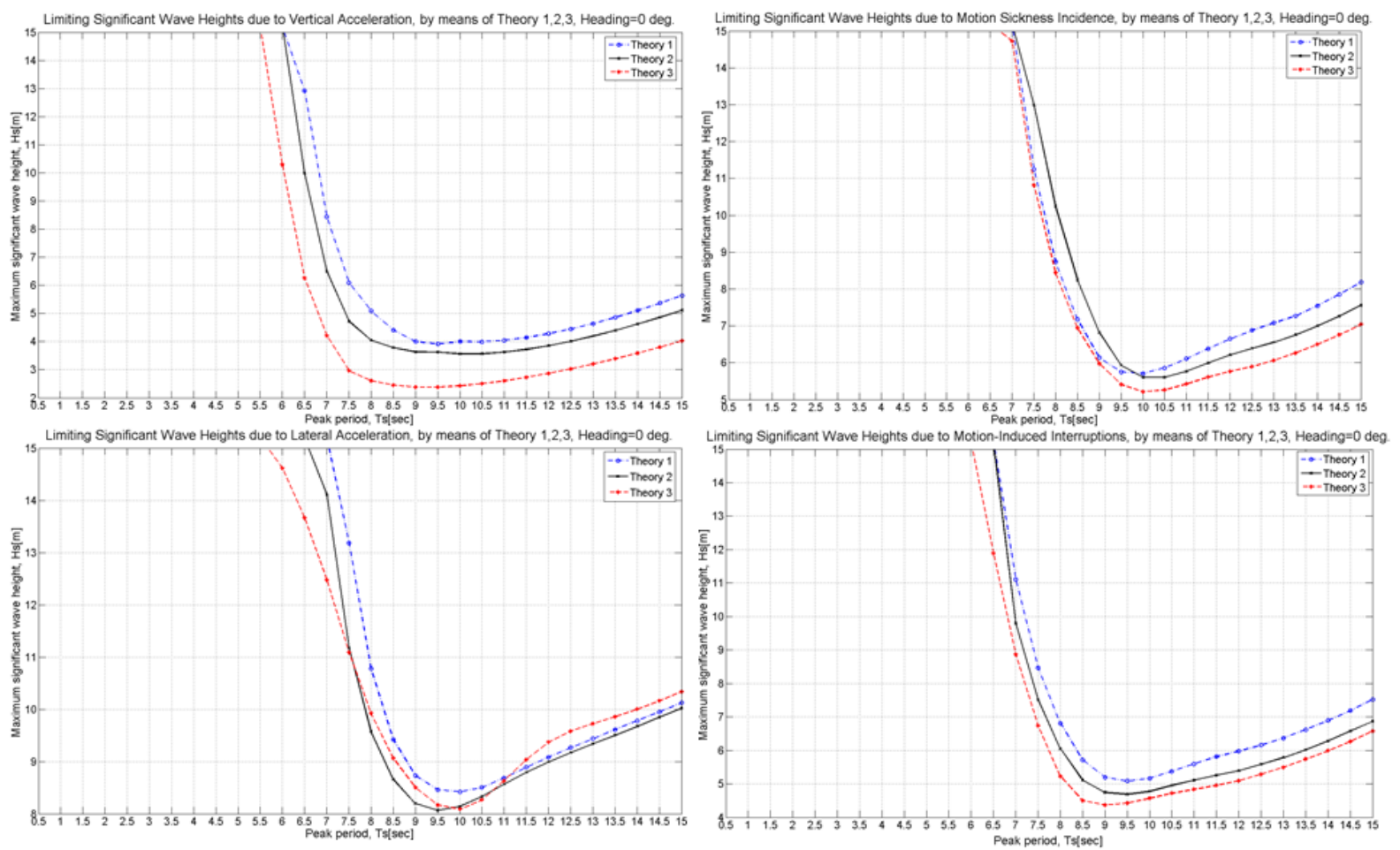

Figure 21. Effect of the employed theories on the limiting significant wave heights.

\subsection{Operability indices}

Operability calculations have been performed, individually, using each theory. The indices for the car/passenger ferry, resulting from these calculations, are summarised in Table 6, which includes both annual and seasonal wave statistics for Area 10, across several headings. In the main columns of the table, the operability indices satisfying each limiting criterion are shown, independently. The overall indices, which decide whether a vessel satisfies all the limiting criteria of interest, are calculated by taking the minimum values of each operability index, and are given on the right-hand block of columns. The average values, which are presented in the bottom row of each table, are calculated by taking the average of the operability indices in each wave heading. It is based on the assumption that each wave heading has an equal probability of occurrence. Using this set of average outputs, the operability results can be compared with each other more efficiently, regardless of the wave heading.

The average annual, spring, summer, autumn and winter operability indices for the ferry are $86.15 \%, 88.67 \%, 91.61 \%, 85.80 \%$ and $83.43 \%$, respectively, when calculated using Theory 3. The results show that the ship is operational, satisfying all necessary criteria, during $86.15 \%$ of a year, on average. A more detailed breakdown for each season is also provided, for example the ship is, on average, operational $83.43 \%$ of the time during winter. When Theory 1 is used to generate RAOs, these indices increase to $95.21 \%, 96.46 \%, 98.60 \%$, $94.73 \%$, and $93.39 \%$. Using Theory 2 , the results alter to $93.80 \%, 95.28 \%, 97.92 \%, 93.31 \%$, and $91.42 \%$, respectively.

As Table 6 shows, the operability is generally small in head and bow seas due to the vertical acceleration at the fore perpendicular. The vessel's operability is highest in following or quarter seas.

It is interesting to note that the overall performance of the vessel is mainly determined by the vertical acceleration. Also, the operability indices calculated solely with regards to the 
vertical acceleration criterion show a remarkably strong dependence on the chosen theory. It should be kept in mind that operability, as a function of limiting criteria, is dependent of predetermined criteria. If the selected threshold values given in Table 4 were lowered, it is obvious that the resultant operability indices would undergo far greater changes when using the employed theories.

Table 6. Operability indices for the car/passenger ferry operating in Area 10.

\begin{tabular}{|c|c|c|c|c|c|c|c|c|c|c|c|c|c|c|c|c|c|c|c|c|c|c|c|c|c|}
\hline \multirow{2}{*}{$\begin{array}{c}\text { Heading } \\
\text { (deg) }\end{array}$} & \multicolumn{5}{|c|}{ Vertical Acceleration } & \multicolumn{5}{|c|}{ MII } & \multicolumn{5}{|c|}{ MSI } & \multicolumn{5}{|c|}{ Lateral Acceleration } & \multicolumn{5}{|c|}{ All criteria } \\
\hline & \begin{tabular}{|l|} 
Year \\
\end{tabular} & Spring & Summer & Autumn & Winter & Year & Spring & Summe & Autumn & Winter & Year & Spring & Summer & Autumn & Winter & Year & Spring & Summer & Autumn & Winter & Year & Spring & Summer & Autumn & Winter \\
\hline $\mathbf{0}$ & 90.42 & 92.62 & 97.15 & 89.45 & 84.40 & 97.30 & 98.12 & & 96.83 & \begin{tabular}{|l|}
95.73 \\
\end{tabular} & 98.22 & 98.92 & & \begin{tabular}{|c|}
97.97 \\
\end{tabular} & 97.28 & 99.72 & 99.92 & 100 & \begin{tabular}{|l|l|}
99.72 \\
\end{tabular} & \begin{tabular}{|c|}
99.66 \\
\end{tabular} & 90.42 & 92.62 & 97.15 & 89.45 & 84.40 \\
\hline 30 & 90.81 & \begin{tabular}{|c|}
92.98 \\
\end{tabular} & 23 & 89.88 & 6.06 & \begin{tabular}{|c|}
95.67 \\
\end{tabular} & 96.88 & 99.03 & 95.06 & 94.04 & 98.37 & 99.07 & 99.84 & 98.20 & 97.89 & 98.68 & 99.32 & 99.92 & 98.62 & 98.57 & 90.81 & 92.98 & 7.23 & 9.88 & $6.0 \mathrm{c}$ \\
\hline 60 & 93.19 & 94.98 & 305 & 92.46 & 91.61 & 94.14 & 95.76 & 98. & 3.50 & 93.23 & 98.86 & 99.37 & 99.93 & 98.80 & 98.96 & 95.34 & 6.68 & 8.79 & 1.76 & 94.29 & 93.19 & 4.98 & .05 & 2.46 & \\
\hline 90 & 97.22 & \begin{tabular}{|c|}
98.20 \\
\end{tabular} & 99.37 & 97.09 & 98.20 & 95.91 & 97.25 & 98.90 & 95.60 & 96.59 & 99.70 & 99.91 & 100 & 99.70 & 99.91 & 94.39 & 96.02 & 3.25 & 3.76 & 93.64 & 4.39 & 6.02 & 3.25 & 3.76 & 3.64 \\
\hline 120 & 99.91 & 100 & & & & 99.08 & 99.49 & 99. & 99.07 & 99.71 & 100 & & & & & 97.65 & & .52 & 97.54 & \begin{tabular}{|l|}
98.03 \\
\end{tabular} & 97.65 & 3.61 & 52 & 97.54 & \\
\hline 15 & \begin{tabular}{|l|}
100 \\
\end{tabular} & 10 & & & & 100 & 100 & & & & 100 & 100 & & & 00 & 100 & & & & 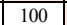 & \begin{tabular}{|l|}
100 \\
\end{tabular} & & & 00 & 00 \\
\hline 180 & 100 & 100 & 100 & 10 & 100 & 100 & 100 & 100 & & & 100 & 100 & & 100 & 100 & 100 & 00 & & 100 & 100 & 100 & 100 & 100 & 100 & 100 \\
\hline verage & 95.94 & \begin{tabular}{|c|}
96.97 \\
\end{tabular} & 98.83 & 95.54 & 94.32 & \begin{tabular}{|c|}
97.44 \\
\end{tabular} & 98.21 & \begin{tabular}{|l}
99.39 \\
\end{tabular} & \begin{tabular}{|l|l}
97.15 \\
\end{tabular} & \begin{tabular}{|c|}
97.04 \\
\end{tabular} & 99.31 & 99.61 & \begin{tabular}{|l|}
99.94 \\
\end{tabular} & 99.24 & \begin{tabular}{|l}
99.15 \\
\end{tabular} & \begin{tabular}{|l|}
97.97 \\
\end{tabular} & \begin{tabular}{|l|}
98.65 \\
\end{tabular} & 99.50 & 97.77 & \begin{tabular}{|l|}
97.74 \\
\end{tabular} & 95.21 & \begin{tabular}{|l|l}
96.46 \\
\end{tabular} & 98.60 & 94.73 & \begin{tabular}{|l|l}
93.39 \\
\end{tabular} \\
\hline
\end{tabular}

\begin{tabular}{|c|c|c|c|c|c|c|c|c|c|c|c|c|c|c|c|c|c|c|c|c|c|c|c|c|c|}
\hline \multirow{3}{*}{\begin{tabular}{|c|}
$\begin{array}{c}\text { Heading } \\
\text { (deg) }\end{array}$ \\
0
\end{tabular}} & \multicolumn{5}{|c|}{ Vertical Acceleration } & \multicolumn{5}{|c|}{ MII } & \multicolumn{5}{|c|}{ MSI } & \multicolumn{5}{|c|}{ Lateral Acceleration } & \multicolumn{5}{|c|}{ All criteria } \\
\hline & \begin{tabular}{|l|} 
Year \\
\end{tabular} & Spring & Summe & Autumn & Winter & Year & Springs & Summet & Autumn & Winter & Year & Spring & Summer & Autumn & Winter & 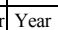 & Spring & Summer & Autumn & Winter & $\begin{aligned} & \mathrm{r} \text { Year } \\
&\end{aligned}$ & Spring & Summe & Autumn & Winter \\
\hline & 86.01 & 88.90 & 94.86 & 85.07 & 78.28 & 96.00 & 97.08 & 99.20 & 95.34 & \begin{tabular}{|l|l|}
93.46 \\
\end{tabular} & 98.06 & 98.66 & 99.70 & 97.69 & 96.36 & 99.67 & 99.87 & 100 & 99.67 & 99.60 & 86.01 & 88.90 & 94.86 & 85.07 & 78.28 \\
\hline 30 & 87.32 & 90.04 & 95.48 & 86.38 & 81.15 & 93.52 & 95.19 & 98.26 & 92.78 & 91.17 & 98.37 & 98.98 & 99.80 & 98.13 & 97.28 & 98.51 & 99.21 & 99.88 & 98.44 & 98.45 & 87.32 & 90.04 & 95.48 & 86.38 & 81.15 \\
\hline 60 & 91.57 & 93.69 & 97.40 & 90.76 & 89.27 & 92.51 & 94.49 & 97.77 & 91.75 & 90.89 & 99.04 & 99.53 & 99.96 & 99.00 & 98.95 & 95.03 & 96.46 & 98.64 & 94.44 & 94.07 & 91.57 & 93.69 & 97.40 & 90.76 & 89.27 \\
\hline 90 & 96.68 & 97.82 & 99.19 & 96.53 & \begin{tabular}{|c|}
97.84 \\
\end{tabular} & 95.30 & 96.74 & 98.64 & 94.88 & 95.78 & 99.83 & 99.96 & 100 & \begin{tabular}{|c|}
99.82 \\
\end{tabular} & \begin{tabular}{|l|l|}
99.92 \\
\end{tabular} & 94.20 & \begin{tabular}{|c|}
95.85 \\
\end{tabular} & 98.19 & 93.55 & 93.41 & 94.20 & 95.85 & 98.19 & 93.55 & 93.41 \\
\hline 120 & 99.88 & \begin{tabular}{|l|}
9.98 \\
\end{tabular} & 100 & 99.88 & 100 & \begin{tabular}{|l|}
99.07 \\
\end{tabular} & 99.48 & 99.91 & \begin{tabular}{|l|}
99.07 \\
\end{tabular} & \begin{tabular}{|l|}
99.69 \\
\end{tabular} & 100 & 100 & 100 & 100 & 100 & \begin{tabular}{|l|}
97.52 \\
\end{tabular} & \begin{tabular}{|l|l|}
98.49 \\
\end{tabular} & 99.49 & 97.38 & 97.83 & 97.52 & 98.49 & 99.49 & 97.38 & 97.83 \\
\hline 150 & \begin{tabular}{|l|}
100 \\
\end{tabular} & \begin{tabular}{|l|}
100 \\
\end{tabular} & 100 & 100 & 100 & 100 & 100 & 100 & 100 & 100 & 100 & 100 & 100 & 100 & 100 & \begin{tabular}{|l|}
100 \\
\end{tabular} & 100 & 100 & 100 & 100 & \begin{tabular}{|l|}
100 \\
\end{tabular} & 100 & 100 & 100 & 100 \\
\hline 180 & $\begin{array}{l}100 \\
\end{array}$ & 100 & 100 & 100 & 100 & 100 & 100 & 100 & 100 & 100 & 100 & 100 & 100 & 100 & 100 & 100 & 100 & 100 & 100 & 100 & 100 & 100 & 100 & 100 & 100 \\
\hline Average & \begin{tabular}{|l|}
94.49 \\
\end{tabular} & \begin{tabular}{|l|l|}
95.78 \\
\end{tabular} & \begin{tabular}{|l|}
98.13 \\
\end{tabular} & 94.09 & \begin{tabular}{|l|}
92.36 \\
\end{tabular} & \begin{tabular}{|l|l|}
96.63 \\
\end{tabular} & \begin{tabular}{|l|} 
\\
\end{tabular} & 99.11 & \begin{tabular}{|l|}
96.26 \\
\end{tabular} & 95.86 & \begin{tabular}{|l|}
99.33 \\
\end{tabular} & \begin{tabular}{|l|}
99.59 \\
\end{tabular} & 99.92 & 99.23 & \begin{tabular}{|l|}
98.93 \\
\end{tabular} & \begin{tabular}{|l|}
97.85 \\
\end{tabular} & \begin{tabular}{|l|}
98.55 \\
\end{tabular} & 99.46 & 97.64 & \begin{tabular}{|l|}
97.62 \\
\end{tabular} & 93.80 & 95.28 & 97.92 & \begin{tabular}{|l|}
93.31 \\
\end{tabular} & \begin{tabular}{|l|l}
91.42 \\
\end{tabular} \\
\hline
\end{tabular}

\begin{tabular}{|c|c|c|c|c|c|c|c|c|c|c|c|c|c|c|c|c|c|c|c|c|c|c|c|c|c|}
\hline \multirow{2}{*}{$\begin{array}{c}\text { Heading } \\
\text { (deg) }\end{array}$} & \multicolumn{5}{|c|}{ Vertical Acceleration } & \multicolumn{5}{|c|}{ MII } & \multirow{2}{*}{\multicolumn{5}{|c|}{ MSI }} & \multirow{2}{*}{\multicolumn{5}{|c|}{ Lateral Acceleration }} & \multirow{2}{*}{\multicolumn{5}{|c|}{ All criteria }} \\
\hline & \begin{tabular}{|l|l|l} 
Year \\
\end{tabular} & Snring & summet & Autump & Winter & Yer & Srringl & Summer & & Winter & Year & S & Summert & & & & Snictas & & & & & & Summert & Autump & \\
\hline 0 & 66.39 & 71.36 & 80.26 & 65.93 & 56.92 & \begin{tabular}{|c|}
93.87 \\
\end{tabular} & 95.45 & 98.39 & 93.12 & 91.23 & 97.39 & 98.15 & 99.56 & 96.84 & 95.05 & 99.60 & \begin{tabular}{|l|}
99.82 \\
\end{tabular} & 100 & 99.60 & 9955 & 66.39 & 71.36 & 80.26 & 65.93 & 56.92 \\
\hline 30 & 68.86 & 73.84 & 81.62 & 68.40 & 61.58 & 92.32 & 94.23 & 97.81 & 91.50 & 89.34 & 97.79 & 98.51 & 99.65 & 97.38 & 96.18 & 98.29 & \begin{tabular}{|l|}
99.03 \\
\end{tabular} & 99.84 & 98.20 & 98.29 & 68.86 & 73.84 & 81.62 & 68.40 & 61.58 \\
\hline 60 & 78.88 & 83.21 & 88.72 & 78.21 & 76.26 & 90.42 & 92.82 & 96.73 & 89.57 & 87.965 & 98.83 & 99.41 & 99.93 & 98.76 & 98.69 & 93.80 & 95.55 & 97.95 & 93.15 & 93.08 & 78.88 & 83.21 & 88.72 & 78.21 & 76.26 \\
\hline 90 & 93.34 & 95.28 & 97.62 & 92.80 & 94.39 & 92.79 & 94.79 & 91.62 & 92.12 & 92.38 & 99.83 & \begin{tabular}{|c|}
99.97 \\
\end{tabular} & 100 & \begin{tabular}{l|l}
99.83 \\
\end{tabular} & \begin{tabular}{|l|}
99.93 \\
\end{tabular} & \begin{tabular}{|c|}
92.27 \\
\end{tabular} & 94.42 & 96.82 & 91.61 & 92.05 & 92.27 & 94.42 & 91.62 & 91.61 & 92.05 \\
\hline 120 & 99.60 & 99.75 & 99.95 & 99.60 & 99.95 & 97.58 & 98.47 & 99.52 & 97.52 & 98.68 & \begin{tabular}{|l|}
100 \\
\end{tabular} & 100 & 100 & 100 & 100 & \begin{tabular}{|l|}
96.69 \\
\end{tabular} & \begin{tabular}{|l|}
97.88 \\
\end{tabular} & 99.05 & 96.48 & \begin{tabular}{|l|}
97.21 \\
\end{tabular} & 96.69 & 97.88 & 99.05 & 96.48 & \begin{tabular}{|l|}
97.21 \\
\end{tabular} \\
\hline 150 & 100 & 100 & 100 & 100 & 100 & 100 & 100 & 100 & 100 & 100 & 100 & 100 & 100 & 100 & 100 & 100 & 100 & 100 & 100 & 100 & \begin{tabular}{|l|}
100 \\
\end{tabular} & 100 & 100 & 100 & 100 \\
\hline 180 & 100 & 100 & 100 & 100 & 100 & 100 & 100 & 100 & 100 & 100 & 100 & 100 & 100 & 100 & 100 & 100 & 100 & 100 & 100 & 100 & 100 & 100 & 100 & 100 & 100 \\
\hline Average & 86.72 & 89.06 & 92.59 & 86.42 & 84.16 & 95.28 & 96.54 & 97.72 & 94.83 & 94.23 & 99.12 & \begin{tabular}{|l|}
99.43 \\
\end{tabular} & 99.88 & 98.97 & \begin{tabular}{|l|}
98.55 \\
\end{tabular} & \begin{tabular}{|l|}
97.24 \\
\end{tabular} & \begin{tabular}{|l|}
98.10 \\
\end{tabular} & 99.10 & 97.01 & 97.17 & 86.15 & 88.67 & 91.61 & 85.80 & 83.43 \\
\hline
\end{tabular}

Also, it can be concluded from Table 6 that the vessel's operability is highest in the summer, closely followed by spring and autumn. Conversely, the vessel has the worst seakeeping performance during winter, as expected.

The data generated using Theory 3, listed in Table 6, is illustrated graphically in Figure 22. This gives a clearer depiction of the overall operability indices of the vessel, enabling a more facile comparison between seasons.

It should be mentioned that in Figures 22-24, the polar axis shows wave headings, whereas the vertical axis shows operability indices. 


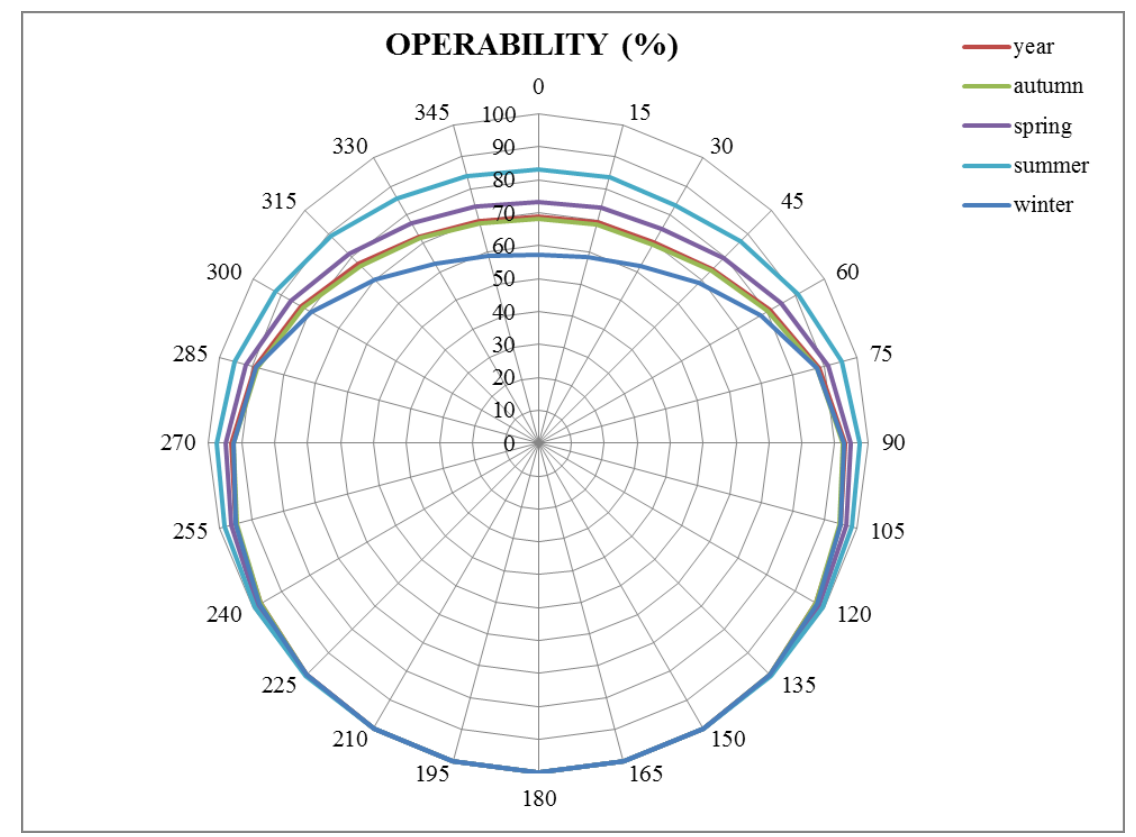

Figure 22. Influence of seasonality on the ship operability (generated using Theory 3 , considering all criteria).

Figure 23 displays the operability polar diagrams of the ferry using the "all criteria" data from Table 6. The figure includes the operability results from all three theories and includes both annual and seasonal results. Shaded areas indicate the area where the ship is operational. The data contained in Table 6 and Figure 23 both express how much the vessel's operability appears to change when using the different theories and the seasonal statistical wave data in the area of interest. 


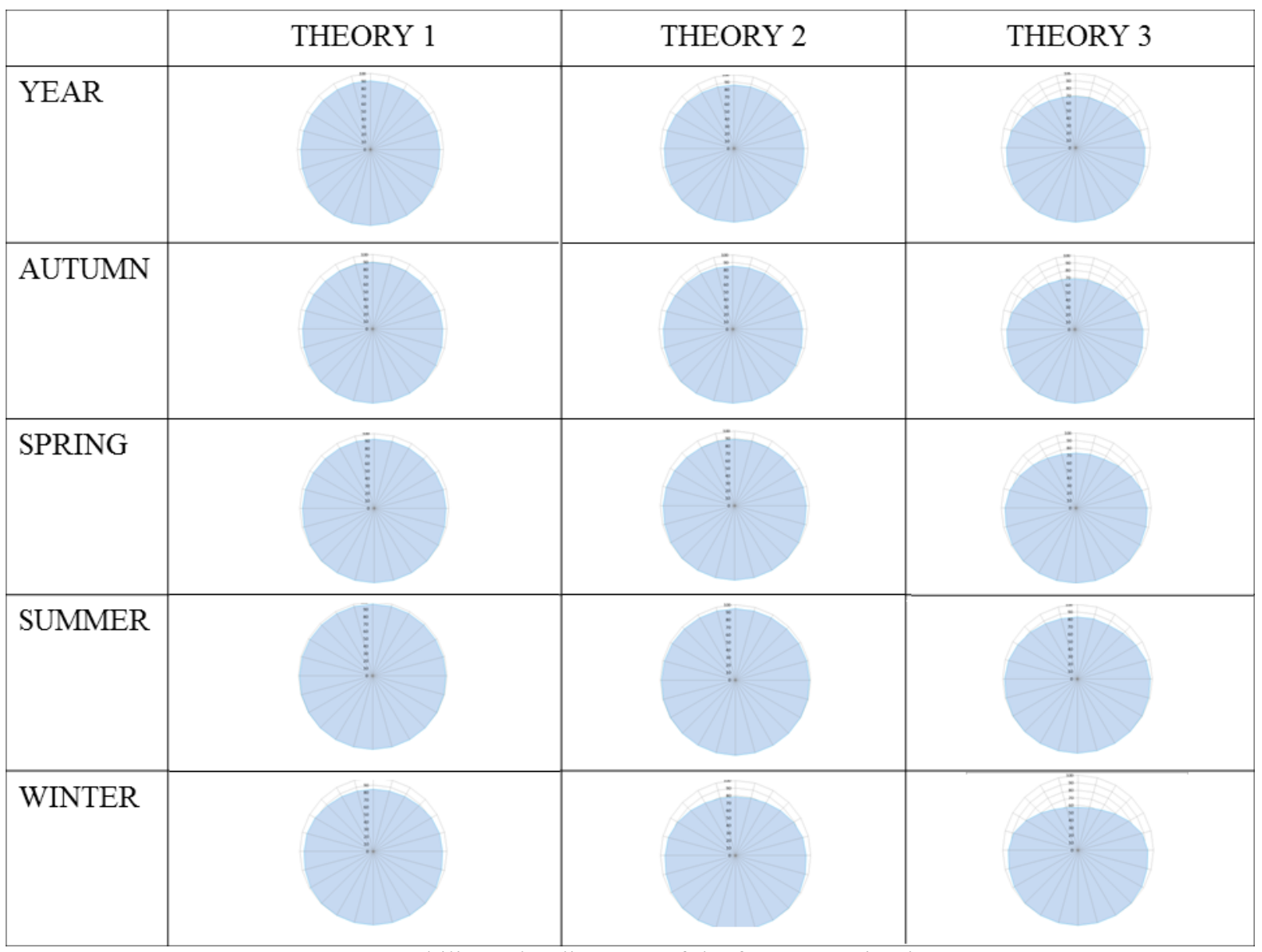

Figure 23. Operability polar diagrams of the ferry operating in Area 10.

Figure 24 examines how a chosen seakeeping method affects subsequent operability analyses, specifically for head seas, and taking into account all selected criteria. According to Figure 24 , changing the method from 2-D classic strip theory to 2.5-D theory which includes hull interactions results in a decrease from $84.40 \%$ to $56.92 \%$ in the operability index, taking into account the winter statistics of Area 10. 


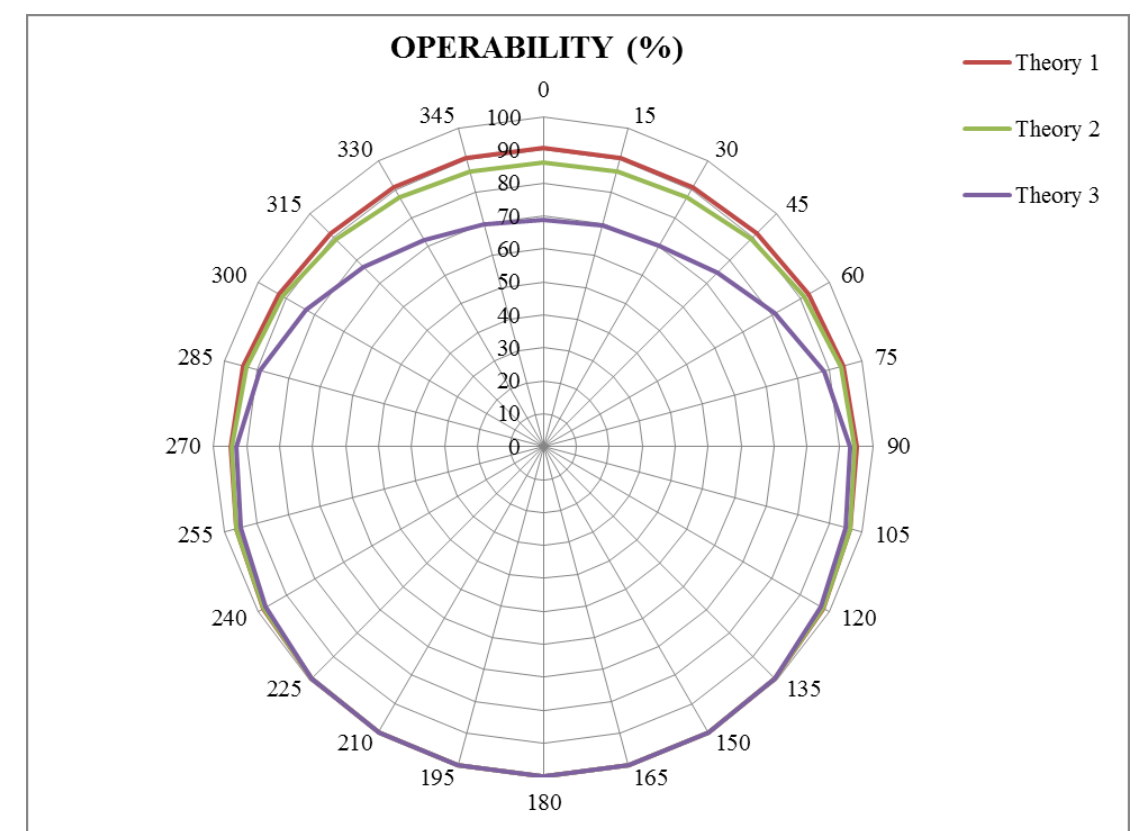

Figure 24. Influence of the different seakeeping techniques on the ship operability.

\subsection{Sensitivity analysis}

Sensitivity analyses show how the operability index of the car/passenger ferry varies with seasonality and the employed theories, in accordance with the results given in Section 5.3. The sensitivity analyses in this sub-section have been conducted in terms of satisfying all limiting criteria.

Figure 25 depicts the sensitivity of the operability index to the selected seakeeping theories. The results obtained using Theory 1 are kept as original values. The vertical axis represents the percentage difference between two theories to the original data, whereas the horizontal axis corresponds to the wave headings. The graph shows the results using annual statistics for the wave climate. It can be concluded from Figure 25 that there is a significant difference in the indices obtained by Theories 2 and 3, compared to those of Theory 1 .

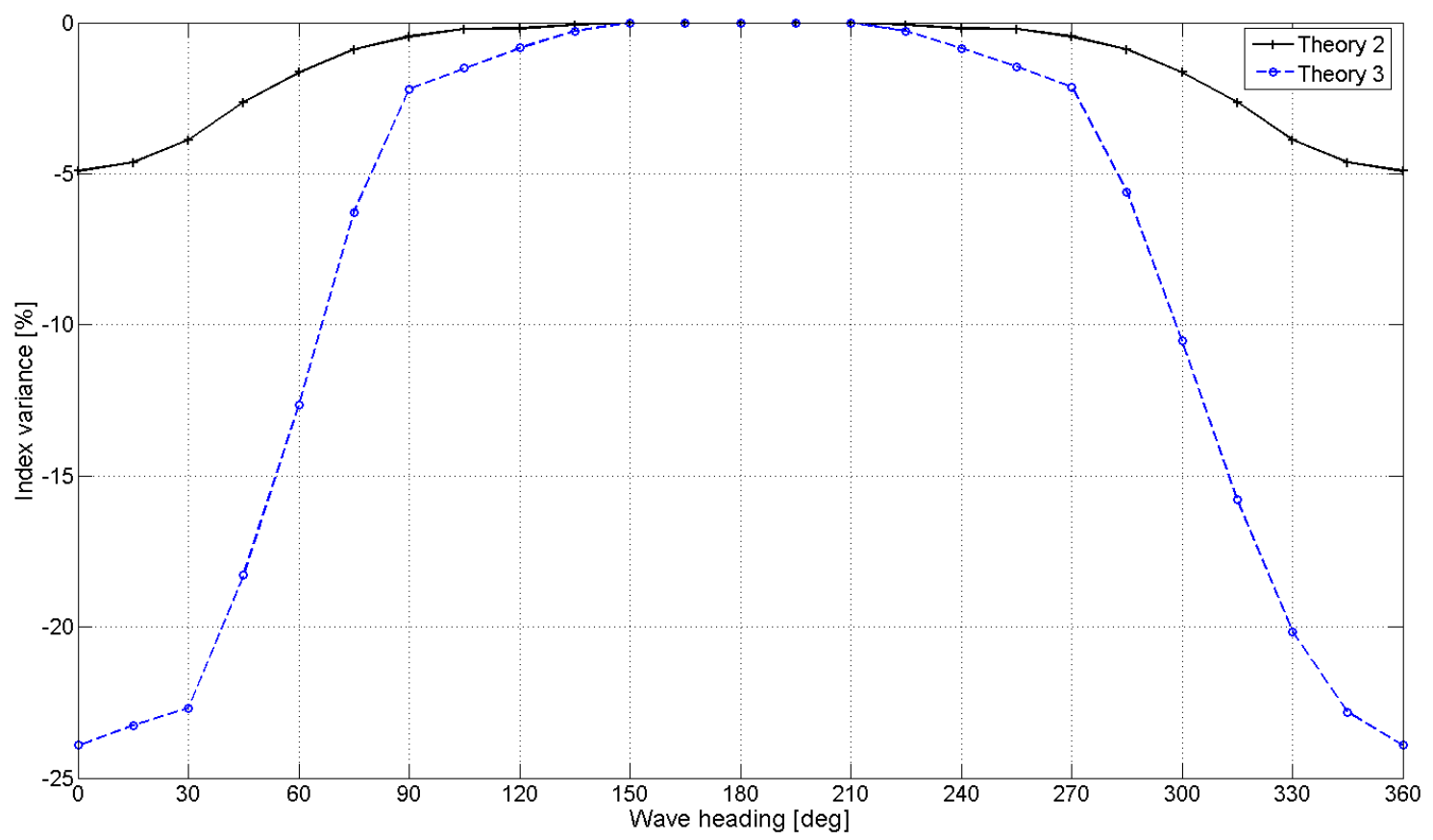

Figure 25. Sensitivity of the operability index to the employed seakeeping theories. 
Figure 26 illustrates how seasonality affects the indices, with the indices obtained using annual wave statistics used as reference data. The sensitivity results are given as a percentage difference relative to the reference values, as a function of heading. The calculations are performed by employing Theory 3 . Figure 26 clearly shows that the indices calculated using the autumn wave scatter data are the closest to those calculated using the annual wave climate data.

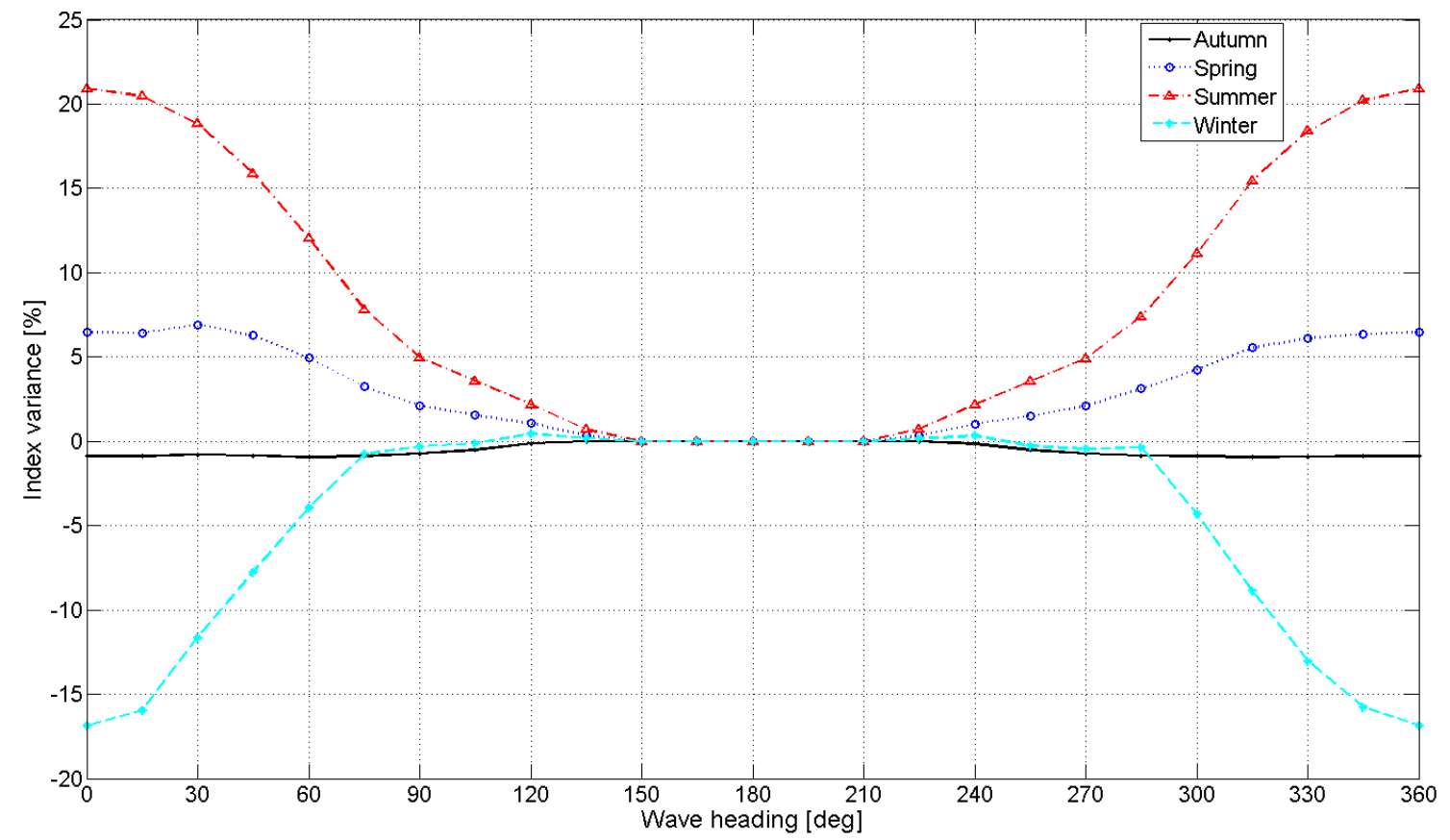

Figure 26. Sensitivity of the operability index to the seasonality.

\section{CONCLUDING REMARKS}

A methodology to calculate the seakeeping performance of ships in a specified sea area where a vessel operates has been presented in this paper. The methodology depends on the response of the vessel to regular waves, the mission features and the wave climate of the sea site.

Three different methods to generate RAOs of the vessel, to be used in the operability analyses, have been chosen and discussed. The limitations and features of each theory have been explained in detail in the literature review. Following this, operability assessments performed to date in the literature have been briefly introduced.

The numerical transfer functions of the ferry, calculated using each theory, have been compared to the experimental data at four different combinations of forward speed and wave heading. The outputs from the comparison show the discrepancies between each applied theory and the experiments. When Theory 2 is compared with Theory 3 , some differences are seen in the calculated heave and pitch motions at the resonance frequency. Numerical prediction of the resonant heave motion is improved when hull interactions are accounted for. Theory 3 therefore shows better agreement with the experimental data compared to Theory 2 . It can also be drawn from the comparison of RAOs that hull interactions are more dominant in heave motion than pitch motion. On the other hand, the discrepancies are larger when hull interactions are taken into account for the roll motions. More interestingly, in most cases, Theory 1 (conventional strip theory) still gives the best numerical results when compared to the experimental results. 
In addition to this, vertical acceleration RAOs in head seas at a range of forward speeds have been calculated, using Theory 1, 2 and 3, individually. Vertical acceleration RAOs obtained using Theory 1 and 2 appear similar to each other, showing a gradual increase with increasing speed. Conversely, vertical accelerations generated using Theory 3 show a different trend. They decrease with increasing speed between a relatively lower speed range, and after this particular range they gradually increase with increasing speed. This is because of the fact that hydrodynamic hull interactions are most significant within this speed range for the ferry, and the waves generated by each demihull affect the vertical accelerations. It has been also shown that for a given frequency of encounter, the wave interaction between demihulls decreases as ship speed increases.

Afterwards, in the results section, the motion sickness incidence values of the vessel have been calculated using each theory. It has been demonstrated that in the low sea states, the MSI results from the different theories appear similar to each other, however in the high sea states, the discrepancies become significant. Theory 3 gives the highest results, whereas Theory 1 gives the lowest result in the high sea states, similar to the vertical accelerations at 20 knots ship speed.

Following this, the limiting significant wave heights due to each criterion have been investigated. It has been seen that the differences in the limiting $\mathrm{H}_{\mathrm{s}}$ using each theory are most pronounced in the vertical acceleration criterion, which also leads to noticeable discrepancies in the resultant operability indices due to vertical acceleration.

Then, operability results, based on human comfort-oriented criteria, have been extensively demonstrated and discussed, using appropriate table and figures in the paper. The results of the operability assessment are given as an operability index which indicates the percentage of time when the vessel is operational. The procedure has been applied to a car/passenger ferry operating near the west coast of Scotland. This work has shown that the overall performance of the vessel in terms of its operability is mainly dominated by the vertical acceleration criterion. The vessel apparently has no crucial problems to meet the other criteria. Given that a vessel's operability is a function of selected limiting values, defining a lower limiting value means obtaining a different operability in return. It should therefore be kept in mind that the findings presented in this work are only valid for the predetermined criteria given in Table 4. Also, the operability analyses have been performed at a forward speed of 20 knots, which coincides with the ship service speed. It should be highlighted that, for instance, if the vessel provides a service at a reduced speed in a higher sea state, then related vertical accelerations may reduce, and hence, in this situation, the vessel may completely satisfy the MSI limiting values in accordance with the ISO criterion.

Finally, in the sensitivity analysis section, the effect of using annual and seasonal wave statistics for the operation site has been demonstrated numerically. Additionally, the sensitivity of the adopted seakeeping theories to the expected vessel's operability has been shown graphically in a comparative manner.

As a future piece of work, a vessel's operability could be predicted by employing more sophisticated methods, such as the 3-D Rankine panel method or the CFD (Computational Fluid Dynamics) based unsteady RANS approach to generate RAOs. The same analyses performed in this work could then be extended by comparing the operability indices by using this more advanced theory, to those from other theories. It would also be interesting to use experimental RAOs to assess ship operability and observe how the results change. 


\section{ACKNOWLEDGEMENTS}

The corresponding author gratefully acknowledges the sponsorship of Izmir Katip Celebi University in Turkey, where he has been working as a research assistant, for giving the Council of Higher Education $\mathrm{PhD}$ Scholarship to fully support his $\mathrm{PhD}$ research at the University of Strathclyde, Glasgow. Additionally, he would like to thank Miss Holly Yu for her help with the final proofreading.

\section{REFERENCES}

Bales, S.L. (1982). Designing Ships to the Natural Environment. David W. Taylor Naval Ship Research and Development Center.

Beck, R.F., Reed, A. (2001). Modern Computational Methods for Ships in a Seaway. Transactions of the Society of Naval Architects and Marine Engineers, Vol. 109, pp. 151.

Bertram, V. (1998). Numerical Investigation of Steady Flow Effects in 3-D Seakeeping Computations. In: Proceedings of $22^{\text {nd }}$ Symposium on Naval Hydrodynamics, pp. 417431, Washington D.C., USA.

Bertram, V., Yasukawa, H. (1996). Rankine Source Methods for Seakeeping Problems. In: Jahrbuch der Schiffbautechnischen Gesellschaft. Springer, pp. 411-425.

Brard, R. (1972). The Representation of a Given Ship Form by Singularity Distributions When the Boundary Condition on the Free Surface is Linearized. Journal of Ship Research, Vol. 16, pp. 79-92.

Chapman, R.B. (1975). Numerical Solution for Hydrodynamic Forces on a Surface-Piercing Plate Oscillating in Yaw and Sway. In: Proceedings of First International Symposium on Numerical Hydrodynamics, pp. 333-350. Gaithersburg, Maryland.

Cummins, W.E. (1956). The Wave Resistance of a Floating Slender Body. Ph.D. Thesis, American University, Washington, D.C.

Dallinga, R.P., Pinkster, D.J., Bos., J.E. (2002). Human Factors in the Operational Performance of Ferries. In: Proceedings of Human Factors in Ship Design and Operation Conference, pp. 89-97, London, England.

Dawson, C.W. (1977). A Practical Computer Method for Solving Ship-Wave Problems. In: Proceedings of $2^{\text {nd }}$ International Conference on Numerical Ship Hydrodynamics, pp. 3038, Berkley, CA, USA.

Faltinsen, O. (2005). Hydrodynamics of High-Speed Marine Vehicles. Cambridge University Press.

Faltinsen, O., Helmers, J.B., Minsaas, K.J., Zhao, R. (1991). Speed Loss and Operability of Catamarans and SES in a Seaway. In: Proceedings of First International Conference on Fast Sea Transportation (FAST'91). Tapir Publisher, pp. 709-725, Trondheim, Norway. 
Faltinsen, O., Hoff, J.R., Kvalsvold, J., Zhao, R. (1992). Global Loads on High Speed Catamarans. In: Proceedings of $5^{\text {th }}$ International Symposium on the Practical Design of Ships and Mobile Units (PRADS'92). Elsevier Science Pubs Ltd, pp. 1.360-1.373, Newcastle upon Tyne, England.

Faltinsen, O., Zhao, R. (1991a). Flow Predictions Around High-Speed Ships in Waves. In: Mathematical Approaches in Hydrodynamics (Ed: Touvia Miloh). Society for Industrial and Applied Mathematics: pp. 265-288. Philadelphia, PA, USA.

Faltinsen, O., Zhao, R. (1991b). Numerical Prediction of Ship Motions at High Forward Speed. Philosophical Transactions: Physical Sciences and Engineering, Vol. 334, pp. 241-257.

Fathi, D. (2004). ShipX Vessel Responses (VERES) Ship Motions and Global Loads Users' Manual. Marintek Report, Norway.

Fathi, D., Hoff, J.R. (2013). ShipX Vessel Responses (VERES) Theory Manual. Marintek Report, Norway.

Fonseca, N., Soares, C.G. (2002). Sensitivity of the Expected Ships Availability to Different Seakeeping Criteria. In: Proceedings of $21^{\text {st }}$ International Conference on Offshore Mechanics and Artie Engineering (OMAE), ASME, Oslo, Norway.

Froude, W. (1861). On the Rolling of Ships. Transactions of Institution of Naval Architects, Vol. 2, pp. 180-229.

Giron, J.M., Esteban, S., Riola, J.M. (2001). Experimental Study of Controlled Flaps and TFoil for Comfort Improvement of a Fast Ferry. In: Proceedings of International Federation of Automatic Control Conference on Control Applications in Marine Systems CAMS01, Glasgow, United Kingdom.

Guevel, P., Vaussy, P., Kobus, J.M. (1974). The Distribution of Singularities Kinematically Equivalent to a Moving Hull in the Presence of a Free surface. International Shipbuilding Progress, Vol. 21(243), pp. 311-324.

Graham, R. (1990). Motion-Induced Interruptions as Ship Operability Criteria. Naval Engineers Journal, Vol. 102(2), pp. 65-71.

Hasselmann, K., Barnett T.P., Bouws, E., Carlson, H., Cart-wright, D.E., Enke, K., Ewing, J.A., Gienapp, H., Hassel-mann, D.E., Kruseman, P., Meerburg, A., Muller, P., Olbers, D.J., Richter, K., Sell, W., Walden, H. (1973). Measurements of Wind-Wave Growth and Swell Decay During the Joint North Sea Wave Project (JONSWAP). Ergnzungsheft zur Deutschen Hydrographischen Zeitschrift Reihe, A(8) (Nr. 12): 95.

Hermundstad, O.A., Aarsnes, J.V., Moan, T. (1999). Linear Hydroelastic Analysis of HighSpeed Catamarans and Monohulls. Journal of Ship Research, Vol. 43(1), pp. 48-63.

Hoff, J. (2014). Personal communication. 
Hogben, N., da Cunha, L.F., Olliver, H.N. (1986). Global Wave Statistics. Brown Union, London.

Ikeda, Y., Takata, H., Ishihara, S. (1991). A Study on Evaluation of Seakeeping Performance for Passenger Ships. Journal of Kansai Society of Naval Architects, Vol. 214, pp. 105112 (in Japanese).

International Organization for Standardization 2631/1 (1997). Mechanical Vibration and Shock-Evaluation of Human Exposure to Whole-Body Vibration.

International Organization for Standardization 2631/3 (1985). Evaluation of Human Exposure to Whole-Body Vibration-Part 3: Evaluation of Exposure to Whole-Body z-axis Vertical Vibration in the Frequency Range 0.1 to $0.63 \mathrm{~Hz}$.

International Towing Tank Conference (ITTC) (1987). Report of the Seakeeping Committee. In: Proceedings of $18^{\text {th }}$ ITTC, Vol. 1, pp. 401-468, Japan.

International Towing Tank Conference (2011). ITTC-Recommended Procedures and Guidelines, Seakeeping Experiment. Revision 04.

Khalid, H., Turan, O., Kurt, R. E. (2009). A Simple Technique for the Operability Analysis of an Offshore Support Vessel Before Deployment at New Sites. In: Proceedings of $13^{\text {th }}$ Congress of the International Maritime Association of the Mediterranean, pp. 961-969, Istanbul, Turkey.

Lloyd, A.R.J.M. (1989). Seakeeping: Ship Behavior in Rough Weather. Ellis Horwood Limited, Chichester, United Kingdom.

Luís, R.M., Teixeira, A.P., Soares, C.G. (2009). Longitudinal Strength Reliability of a Tanker Hull Accidentally Grounded. Structural Safety, Vol. 31, pp. 224-233, doi: 10.1016/j.strusafe.2008.06.005.

McCauley, M.E., Royal, J.W., Wylie, C.D., O’Hanlon, J.F., Mackie, R.R. (1976). Motion Sickness Incidence: Exploratory Studies of Habituation, Pitch and Roll, and the Refinement of a Mathematical Model. Technical Report 1733-2, Human Factors Research Inc., Goleta, California.

McTaggart, K. (1997). Shipmo7: An Updated Strip Theory Program for Predicting Ship Motions and Sea Loads in Waves. DREA Technical Memorandum 96/243, Defence Research Establishment Atlantic Dartmouth.

Mortola, G., Khalid, H., Judah, S., Incecik, A., Turan, O. (2012). A Methodology for Rapid Selection of a Seaworthy Vessel for Offshore Wind Turbine Construction, Operation and Maintenance. In: Proceedings of Second Marine Operations Specialty Symposium (MOSS 2012), Singapore, doi: 10.3850/978-981-07-1896-1_MOSS-30.

Newman, J.N. (1964). A Slender-Body Theory for Ship Oscillations in Waves. Journal of Fluid Mechanics, Vol. 18(4), pp. 602-618. 
Newman, J.N. (1978). The Theory of Ship Motions. Advances in Applied Mechanics, Vol. 18 , pp. 221-283.

O'Hanlon, J. F., McCauley, M. E. (1974). Motion Sickness Incidence as a Function of the Frequency and Acceleration of Vertical Sinusoidal Motion. Aerospace Medicine, Vol. 45(4), pp. 366-369.

Riola, J.M., Arboleya, M.G. (2006). Habitability and Personal Space in Seakeeping Behaviour. Journal of Maritime Research, Vol. 36(1), pp. 41-54.

Salvesen, N., Tuck, E.O., Faltinsen, O. (1970). Ship Motions and Sea Loads. Transactions of the Society of Naval Architects and Marine Engineers, Vol. 78, pp. 250-287.

Sarioz, K., Sarioz, E. (2005). Habitability Assessment of Passenger Vessels Based on ISO Criteria. Marine Technology, Vol. 42(1), pp. 43-51.

Sclavounos, P.D. (1984). The Diffraction of Free-Surface Waves by a Slender Ship. Journal of Ship Research, Vol. 28(1), pp. 29-47.

Sclavounos, P.D. (1985). The Unified Slender-Body Theory: Ship Motions in Waves. In: Proceedings of $15^{\text {th }}$ Symposium on Naval Hydrodynamics, pp. 177-192, Hamburg, Germany.

Soares, C.G., Fonseca, N., Centeno, R. (1995). Seakeeping Performance of Fishing Vessels in the Portuguese Economic Zone. In: Proceedings of International Conference on Seakeeping and Weather, paper 12, pp. 1-10, London, England.

St Denis, M., Pierson, W. (1953). On the Motions of Ships in Confused Seas. Transactions of the Society of Naval Architects and Marine Engineers, Vol. 61, pp. 280-354.

Tezdogan, T., Demirel, Y.K., Mortola, G., Incecik, A., Turan, O., Khalid, H. (2013). Chapter 31. Operability Analysis of a High Speed Car/Passenger Ferry. In: Developments in Maritime Transportation and Exploitation of Sea Resources (Ed: Soares, C.G. and Peña, F.L.). pp. 273 -281, doi: 10.1201/b15813-36.

Vugts, J.H. (1968). The Hydrodynamic Coefficients for Swaying, Heaving and Rolling Cylinders in a Free Surface. Report No. 194. Shipbuilding Laboratory, Delft University of Technology, Delft.

Wang, Z.H. (2000). Hydroelastic Analysis of High-Speed Ships. Ph.D. Thesis, Technical University of Denmark, Lyngby, Denmark.

Yasukawa, H. (2003). Application of a 3-D Time Domain Panel Method to Ship Seakeeping Problems. In: Proceedings of $24^{\text {th }}$ Symposium on Naval Hydrodynamics, pp. 376-392, Fukuoka, Japan.

Yeung, R.W., Kim, S.H. (1985). A New Development in the Theory of Oscillating and Translating Slender Ships. In: Proceedings of $15^{\text {th }}$ Symposium on Naval Hydrodynamics, pp. 195-218, Hamburg, Germany. 